NBSIR 78-1433

\title{
Low Velocity Performance of a Bronze Bearing Vane Anemometer
}

Prepared for

United States Department of the Interior

Bureau of Mines

by

L. P. Purtell

National Bureau of Standards

Fluid Mechanics Section

Washington, D.C. 20234

February 1978

Task Report

on

Contract No. HO166198

Evaluation of the BEhavior of Mine Anemometers in the NBS Low Velocity Calibration Facility 


\section{DISCLAIMER NOTICE}

The views and conclusions contained in this document should not be interpreted as necessarily representing the official policies or recommendations of the Interior Department's Bureau of Mines. 


\section{LOW VELOCITY PERFORMANCE OF A BRONZE BEARING VANE}

\section{ANEMOMETER}

L. P. Purtell

Fluid Mechanics Section

Mechanics Division

Institute for Basic Standards

National Bureau of Standards

Washington, D.C. 20234

February 1978

Task Report

Prepared for

United States Department of the Interior

Bureau of Mines

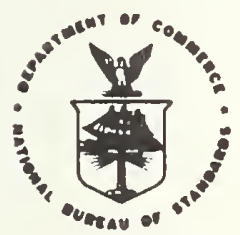

U.S. DEPARTMENT OF COMMERCE, Juanita M. Krops, Secretary Dr. Sidney Harman, Undor Socrotary

Jordan J. Baruch, Assistent Secrotary for Scionce and Technology

NATIONAL BUAEAU OF STANDARDS, Ernest Ambler, Director 



\section{- FOREWORD -}

This report was prepared by the National Bureau of Standards, Fluid Mechanics Section, Washington, D. C. 20234, under USBM Contract Number H0166198. The contract was initiated under the Coal Mine Health and Safety Program. It was administered under the technical direction of PM\&SRC, with Dr. George H. Schnakenberg, Jr., acting as the Technical Project officer. Mr. H. R. Eveland was the contract administrator for the Bureau of Mines.

This report is a summary of the work recently completed as part of this contract during the period December 1, 1976 to February 28, 1977. This report was submitted by the author February 1978. 



\section{LIST OF SYMBOLS}

U

$U_{i}$

Uif

$\mathrm{m}, \mathrm{a}, \mathrm{U} *, \mathrm{U}_{\mathrm{O}}$

$\overline{\mathrm{U}}$

$\sigma$

$\sigma_{c}$

$\mathrm{U}_{\mathrm{O}}, \mathrm{U}_{\text {io }}$

$\mathrm{U}_{\mathrm{r}}, \mathrm{U}_{\text {ir }}$

$\delta U_{r}$

$\delta U_{\text {ir }}$

s.

$\sigma_{\mathrm{u}}$

velocity measured by laser velocimeter

velocity indicated by anemometer under test

curve fitted to $U, U_{i}$ data

constants involved in curve $f i t, U_{\text {if }}$

group mean velocity

standard deviation of $U_{i}$ data from $U_{i f}$

$\sigma$ adjusted for known variance in laser velocimeter measurements (see Appendix)

a point on $U_{\text {if }}(U)$

an actual measurement

$\mathrm{U}_{\mathrm{r}}-\mathrm{U}_{\mathrm{O}}$

$\mathrm{U}_{\text {ir }}-\mathrm{U}_{\text {io }}$

(see Appendix)

standard deviation of laser velocimeter measurements 


\title{
LOW VELOCITY PERFORMANCE OF A BRONZE BEARING VANE ANEMOMETER
}

\author{
L. P. Purtell
}

\section{INTRODUCTION}

The National Bureau of Standards in order to meet the need for a calibration capability with adequate accuracy at low air velocities, i.e., below 500 feet per minute (fpm) undertook the development of a low-velocity calibration facility for wind speed measuring instruments which would provide a capability down to 3 meters per minute (approximately $10 \mathrm{fpm}$ ) with an accuracy of plus or minus one percent. It was a natural consequence therefore that when said facility became operational to undertake an evaluation of the state-of-the-art, and to provide the information needed as to the reliability and performance of instrumentation for such measurement. Accordingly, a number of prototypes of various types of instruments for low velocity air measurements are undergoing test at NBS, and this report is concerned specifically with the results of one such test.

\section{THE INSTRUMENT}

The rotary vane anemometer tested for this report is a commercially available instrument (Davis Instrument Manufacturing Co., Inc., 4-Inch Low Speed Anemometer, S/N 22889) ${ }^{l}$ used in the mining industry and elsewhere as a portable anemometer. It was supplied for test by the U.S. Mining Enforcement and Safety Administration (MESA) at the request of the U.S. Bureau of Mines. The housing is 4 inches in diameter and $1-3 / 4$ inches deep (Figure 1). Thin metal vanes without camber or twist mounted on arms drive a rotor linked to a dial indicator by a gear train. The bearings in this particular instrument are standard bronze bearings (as opposed to ball bearings). One revolution on the dial represents an indicated passage of 100 feet of air through the instrument. Thus an external timer (not a part of the anemometer) is required to complete a measurement of velocity (an average velocity for the duration of the measurement).

1 This particular instrument was selected as being representative of this type of anemometer and 1 ts selection does not represent an endorsement. 


\section{THE TESTS}

The NBS Low Velocity Airflow Facility [1] ${ }^{2}$ used to test this instrument generates a low velocity air stream having a low turbulence intensity (less than $0.05 \%$ ) and a large region of uniform flow (at least $75 \times 75 \mathrm{~cm})$. A laser velocimeter is employed as a primary velocity standard. In addition, it is nonintrusive, has a linear response with velocity, and has good spatial resolution. Adequate sensitivity is obtained without the artificial seeding of scattering particles. Thus the difficulties and inconvenience associated with seeding and the possible effect of such seeding on the performance of the device under test are avoided.

The vane anemometer was mounted on the centerline of the tunnel test section one meter downstream of the entrance to the test section in a manner to minimize the effect of the support on the air stream around the anemometer (Figure 1). Since the anemometer itself modifies the airflow in the tunnel, the velocity should be measured at a location in the flow which has the same velocity in the presence of the anemometer as it does in the absence of the anemometer. Thus the velocity upstream of the anemometer on the centerline was measured to find the position where deceleration of the flow due to the presence of the anemometer was no longer perceptible. These measurements were performed at two freestream speeds, 700 and $72 \mathrm{fpm}$, and as predicted by ideal flow theory the variation of the ratio of the local velocity to the free-stream velocity with distance upstream of the anemometer is independent of free-stream velocity (Figure 2). A distance of $30 \mathrm{~cm}$ upstream of the anemometer was chosen as the position for velocity measurement by the laser velocimeter. With no anemometer in the tunnel, variation in velocity along the centerline is imperceptible over the distance traversed $(30 \mathrm{~cm})$.

The air speed indicated by the vane anemometer was computed from initial and final readings of the dial and of the associated time interval (around two minutes). The anemometer runs continuously in the tunnel since it cannot be accessed while the tunnel is in operation without disturbing the flow. Thus the readings of the anemometer were performed with the anemometer in operation. The laser velocimeter measurement of the air velocity was performed during the time interval for reading the vane anemometer. Five separate test runs were made, each consisting of about nine such measurements over the range 64 to $690 \mathrm{fpm}$. The lower velocity was limited by the starting and stopping speeds of the instrument. The data are presented in chronological order in Tables $1 \mathrm{~A}$ to $1 \mathrm{E}$.

2 Figures in brackets represent literature references at the end of this paper. 
To determine the starting speeds of the instrument, the velocity in the tunnel was increased from below the starting speed at a smooth acceleration of approximately $30 \mathrm{fpm} / \mathrm{min}$ until movement of the vanes could be detected by eye. At that moment the air velocity would be fixed and the laser velocimeter measurements initiated. If the anemometer continued rotating for at least thirty seconds and did not decelerate, the measurement of velocity by the laser velocimeter was recorded as the starting speed. Ten such measurements are presented in Table 2 and have an average of $63.3 \mathrm{fpm}$ and a standard deviation of $3.3 \mathrm{fpm}$.

Because of the anemometer's angular momentum, stopping speed is more difficult to determine than starting speed. Some preliminary runs indicated that a two minute interval between reductions in air velocity of approximately $2 \mathrm{fpm}$ was sufficient for the anemometer to come to rest if the stopping speed had been reached. Ten such measurements are presented in Table 3 with an average of $54 \mathrm{fpm}$ and a standard deviation of $2 \mathrm{fpm}$.

\section{TEST RESULTS}

Since a particular air speed in the wind tunnel cannot be exactly reset from run to run, scatter in the test data is distributed along a curve, thus prohibiting computing the standard deviation of the data from a simple average. Instead, deviations from a curve fit to the data were computed and the standard deviation defined to be the r.m.s. value of a group of these deviations. To accomplish this, an expression was chosen to approximate the relation between the true and indicated velocities which reflected the linear relationship at the higher speeds but allowed for deviation from the linear at the lower speeds. This expression and the four parameters it contalns were developed solely for the statistical analysis of the data and are not meant to represent any characteristics of the instrument's performance.

A curve of the form

$$
U_{\text {if }}=m\left(U-U^{*}\right)\left\{1-\exp \left[-a\left(U-U_{0}\right)\right]\right\}
$$

was fit to the data, where $U$ is the true velocity, $U_{i f}$ is the fitted indicated velocity, and $\mathrm{m}, \mathrm{a}, \mathrm{U}^{*}$, and $\mathrm{U}_{\mathrm{O}}$ are constants to be determined. Since $U_{\text {if }}$ asymptotically approaches the ${ }^{\circ}$ ine

$$
m\left(U-U^{*}\right)
$$

at the higher speeds above $150 \mathrm{fpm}$, a linear least-squares fit of the data was employed to determine $m$ and $U^{*}$. $U_{0}$ and a were then chosen to 
give a good fit (by eye) to the two lowest groups of data (U < $150 \mathrm{fpm}$ ). The resulting values are

$$
\begin{aligned}
\mathrm{m} & =1.10 \\
\mathrm{U}^{*} & =20.6 \mathrm{fpm} \\
\mathrm{U}_{\mathrm{O}} & =53 \mathrm{fpm} \\
\mathrm{a} & =.0431 \mathrm{fpm}^{-1}
\end{aligned}
$$

One data point, the first in Table $1 E$, was omitted from these calculations because it lies outside the $3 \sigma$ limit. No explanation for this large deviation can be offered. The fitted curve and the data are presented in Figure 3.

To determine the standard deviation, $\sigma$, of the indicated velocity, $U_{i}$, about the fitted curve, $U_{i f}$, the squared differences between the $U_{\text {, data }}{ }^{\prime}$ and $U_{i f}$, i.e. $\left[U_{i}(U)-U_{i f}(U)\right]^{2}$, were computed and grouped in the following five groups

$$
\begin{aligned}
& \mathrm{U}<80 \mathrm{fpm} \\
& 80 \mathrm{fpm}<\mathrm{U}<100 \mathrm{fpm} \\
& 100 \mathrm{fpm}<\mathrm{U}<300 \mathrm{fpm} \\
& 300 \mathrm{fpm}<\mathrm{U}<600 \mathrm{fpm} \\
& 600 \mathrm{fpm}<\mathrm{U} .
\end{aligned}
$$

Since the groups are reasonably compact (small range of $U$ within a group; see Figure 3.), the mean of the squared differences within a group was taken as an estimate of the variance of $U_{i}$ about $U_{i f}$ within that group and specified at that group's mean true velocity, $\bar{U}$. The square roots of the estimates, $\sigma$, are presented in Figure 4 as velocity and Figure 5 as percentage of $\bar{U}$. Since $\pm 2 \sigma$ is extremely close to the 95 percent confidence interval for one measurement, curves of $\pm 2 \sigma$ are also included in Figure 3 as dashed lines.

The scatter in the velocity data includes contributions from the laser velocimeter as well as the anemometer; however, an estimate of the standard deviation of the anemometer measurements may be obtained by accounting for the standard deviation of the laser velocimeter data estimated from repeated measurements of velocity at a particular fan setting, thus also including any unsteadiness in the velocity. As shown in the Appendix, the corrected variance for the anemometer $\sigma_{c}{ }^{2}$, may be computed from 


$$
\sigma_{c}^{2}=\sigma^{2}-\left(\frac{\partial U_{i f}}{\partial U}\right) \sigma_{c}{ }^{2}
$$

where $\sigma_{u}$ is the standard deviation of the laser velocimeter measurements, i.e. .005U over the range of velocity measured herein. The dashed curves in Figures 4 and 5 show the values of $\sigma$ and $\sigma / \bar{U}$, respectively. The adjustment in $\sigma$ is small at the lower vêlocitiés indicating that the scatter at the very low velocities is almost entirely due to the anemometer.

The actual differences between the true and indicated velocities, $U-U_{1}$, are presented in Figure 6 and as a percentage of $U$ in Figure 7 . The curves shown in each figure have been fitted to the data by using equation (1).

\section{DISCUSSION OF RESULTS}

The instrument performed as intended with no erratic behavior. The starting and stopping speeds were quite consistent considering the difficulty in determining them with precision. Some general comments concerning application of the instrument follow. With any measurement problem the instrument's capabilities should be matched to the required measurement.

This anemometer is intrusive, i.e., it must be placed in the flow.

This anemometer is entirely mechanical and does not require an outside source of power.

Many other factors that can affect the suitability of an instrument for a particular application, such as turbulence or unsteadiness of the air stream, rough handling (shock and vibration), dirt and other environmental factors, time, orientation to the velocity and gravity vectors, etc., have not been tested herein but should be considered.

\section{SUMMARY}

The performance of a 4-inch diameter low speed vane anemometer with bronze bearings has been evaluated, including starting speed and stopping speed, at air speeds up to $690 \mathrm{fpm}$.

The starting and stopping speed measurements are presented and give an average starting speed of $63.3 \mathrm{fpm}$ and an average stopping speed of $54 \mathrm{fpm}$.

\section{REFERENCES}

1. L. P. Purtell and P. S. Klebanoff, The NBS Low Velocity Airflow Facility, in preparation. 


\section{APPENDIX}

Correction in o for Variance in Laser Velocimeter Measurements

If a great number of velocity measurements were made by the anemometer under test, $U_{\mathcal{I}}$, and the laser velocimeter, $U$, a curve, $U_{\text {if }}(U)$ could be drawn through a cross-plot of the data, eg., by a least-squares fit, representing the expected values of pairs of such measurements. Thus at a particular setting of the air velocity in the tunnel an expected pair of measurements, $U_{0}$ and $U_{i o}$, could be determined from the curve. Actual velocity measurements by the two instruments, $U$ and $U_{i}$, would deviate randomly from the expected values. The $r$ th of $N$ such measurements could be written

$$
\begin{aligned}
& \mathrm{U}_{\mathrm{r}}=\mathrm{U}_{\mathrm{o}}+\delta \mathrm{U}_{\mathrm{r}} \\
& \mathrm{U}_{\mathrm{ir}}=\mathrm{U}_{i o}+\delta \mathrm{U}_{\mathrm{ir}}
\end{aligned}
$$

where $\delta U_{r}$ is the deviation of $U_{r}$ from $U_{0}$ and $\delta U_{i r}$ is the deviation of $U_{\text {ir }}$ from $\mathrm{U}_{10}$. For small deviations from the expected values a one-term Taylor expansion of $U_{\text {if }}(U)$ about the point $\left(U_{0}, U_{i o}\right.$ ) leads to (see figure below)

$$
s_{r}=\delta U_{i r}-\left(\frac{\partial U_{i f}}{\partial U}\right)_{0} \delta U_{r}
$$

where $s$ is the measured deviation of the data point from the fitted curves (approximately) and $\left(\partial U_{i f} / \partial U\right)_{0}$ is $\left(\partial U_{i f} / \partial U\right)$ evaluated at $U_{0}$.

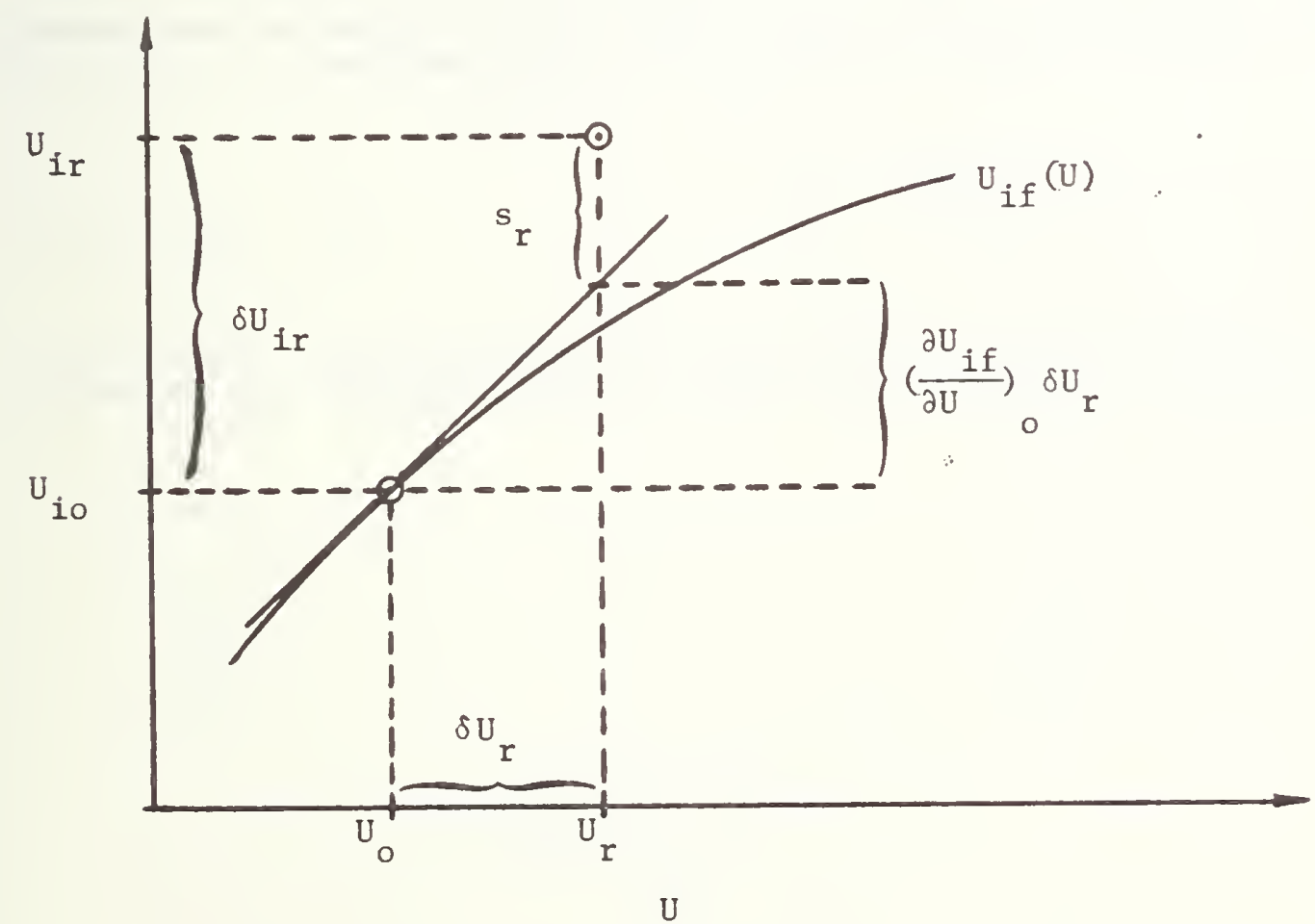


Thus

$$
s_{r}^{2}=\left(\delta U_{i r}\right)^{2}+\left(\frac{\partial U}{\partial U}\right)_{0}^{2} \delta U_{r}^{2}-2 \delta U_{i r}\left(\frac{\partial U_{i f}}{\partial U}\right)_{0} \delta U_{r}
$$

Summing $\mathrm{N}$ such expressions and dividing by $\mathbb{N}$ gives

$$
\begin{aligned}
& \frac{1}{N} \sum_{r=1}^{N} s_{r}^{2}=\frac{1}{N} \sum_{r=1}^{N}\left(\delta U_{i r}\right)^{2}+\left(\frac{\partial U_{i f}}{\partial U}\right)_{0}^{2} \frac{1}{N} \sum_{r=1}^{N}\left(\delta U_{r}\right)^{2} \\
& -2\left(\frac{\partial U_{i f}}{\partial U}\right)_{0} \frac{1}{N} \sum_{r=1}^{N} \delta U_{i r} \delta U_{r} .
\end{aligned}
$$

Since the deviations in the two instruments are independent, the last term on the right is zero. The term on the left side has been defined in this report as $\sigma^{2}$ (within the Taylor expansion approximation). The first term on the right is the corrected value of the variance in anemometer measurements, $\sigma^{2}$ (which would equal $\sigma^{2}$ if the laser velocimeter had no scatter at alI), and the summation divided by $N$ in the second term on the right is the known variance in laser velocimeter measurements, $\sigma^{2}$. Thus the variance in the anemometer measurements corrected for a known variance in the laser velocimeter measurements is

$$
\sigma_{c}^{2}=\sigma^{2}-\left(\frac{\partial U}{\partial U}\right)^{2} \sigma_{u}^{2}
$$

It should be noted that if $\partial U U_{f f} / \partial U=1$ (approximately true in some instances) the usual formula fnvolving the difference in variances is obtained. 
Table 1A

Davis Vane Anemometer

Serial No. 22889

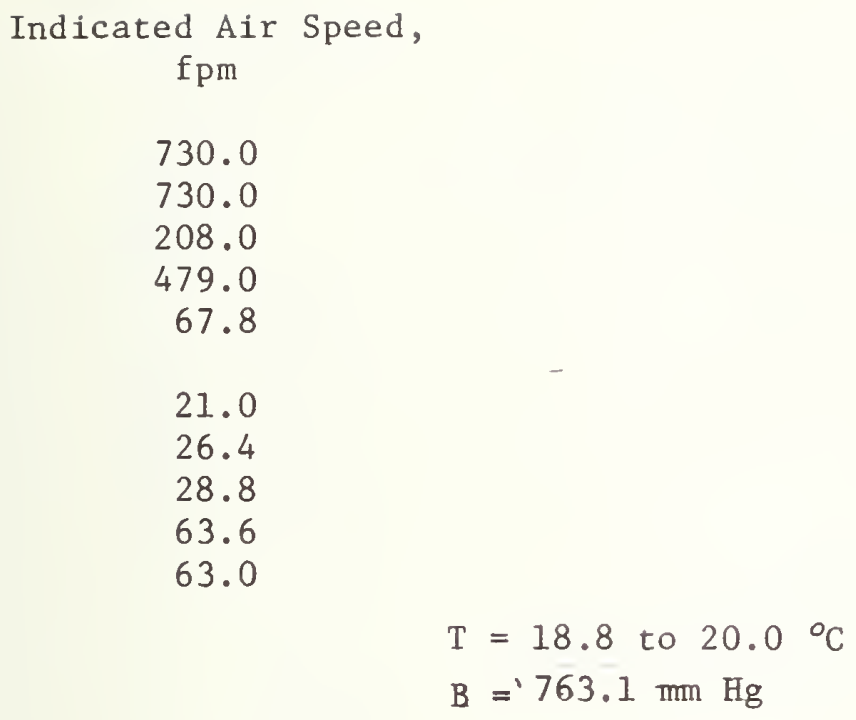

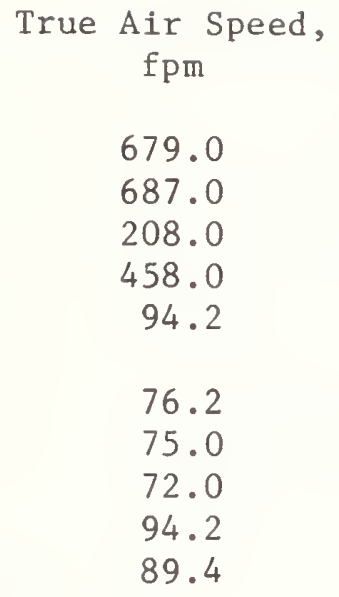


Table 1C

Davis Vane Anemometer

Serial No. 22889
Indicated Air Speed,

fpm

732.0

211.0

482.0

70.2

39.3

36.5

29.6

69.6

68.4
True Air Speed, fpm

690.0

207.0

458.0

94.8

72.0

73.2

76.2

96.0

96.6

$$
\begin{aligned}
& \mathrm{T}=21.0{ }^{\circ} \mathrm{C} \\
& \mathrm{B}=755.0 \mathrm{~mm} \mathrm{Hg}
\end{aligned}
$$

Table 1D

Davis Vane Anemometer

Serial No. 22889
Indicated Air Speed, fpm

735.0

210.0

481.0

69.6

39.1

44.0

45.3

70.8

70.8
True Air Speed, $\mathrm{fpm}$

687.0

214.0

460.0

94.2

75.6

76.8

75.6

96.6

96.6

$$
\begin{aligned}
& \mathrm{T}=21.6{ }^{\circ} \mathrm{C} \\
& B=764.0 \mathrm{~mm} \mathrm{Hg}
\end{aligned}
$$


Table lE

Davis Vane Anemometer

Serial No. 22889

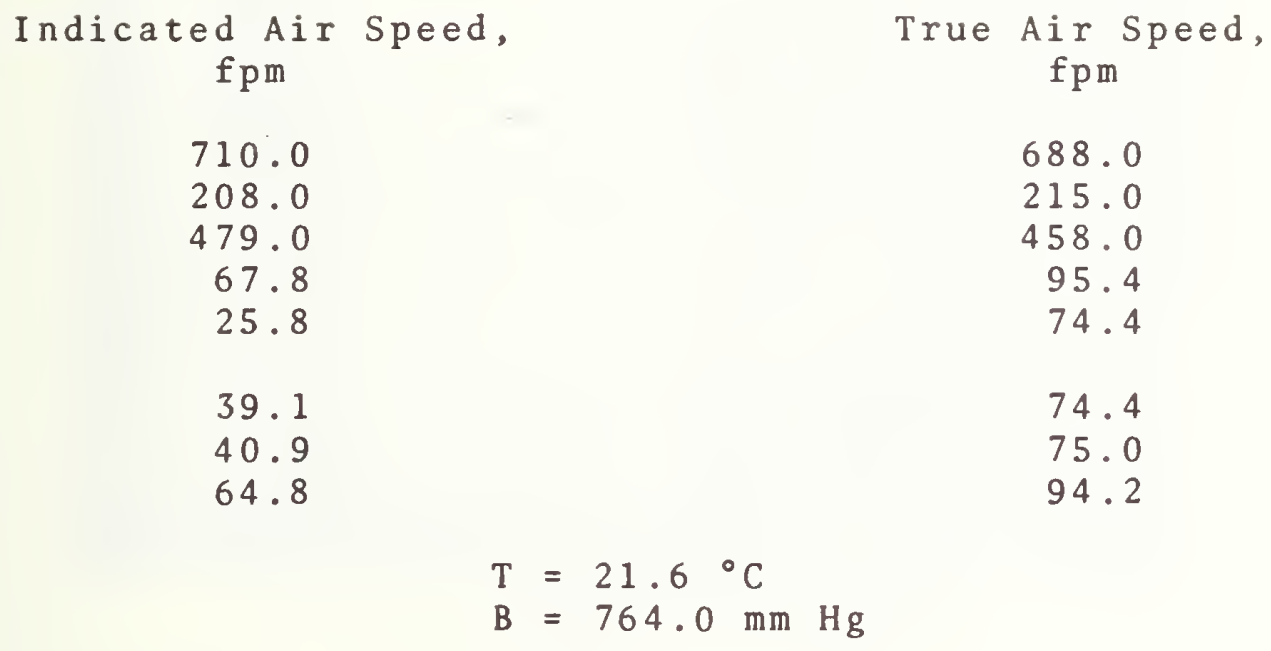




\section{Table 2}

\section{Davis Vane Anemometer}

Serial No. 22889

\section{Starting Speed, f pm}

67.2

63.6

63.6

56.4

66.0

63.6

66.0

63.6

58.8

64.2

Average Starting Speed

$63.3 \mathrm{fpm}$

Standard Deviation

$3.3 \mathrm{fpm}$

Table 3

Dav1s Vane Anemometer

Serial No. 22889

\section{Stopping Speed,} f pm

55.7

51.7

54.1

53.4

57.5

57.4

51.6

55.8

53.5

54.0
Average Stopping Speed $54 \mathrm{fpm}$

Standard Deviation

$2 \mathrm{fpm}$ 


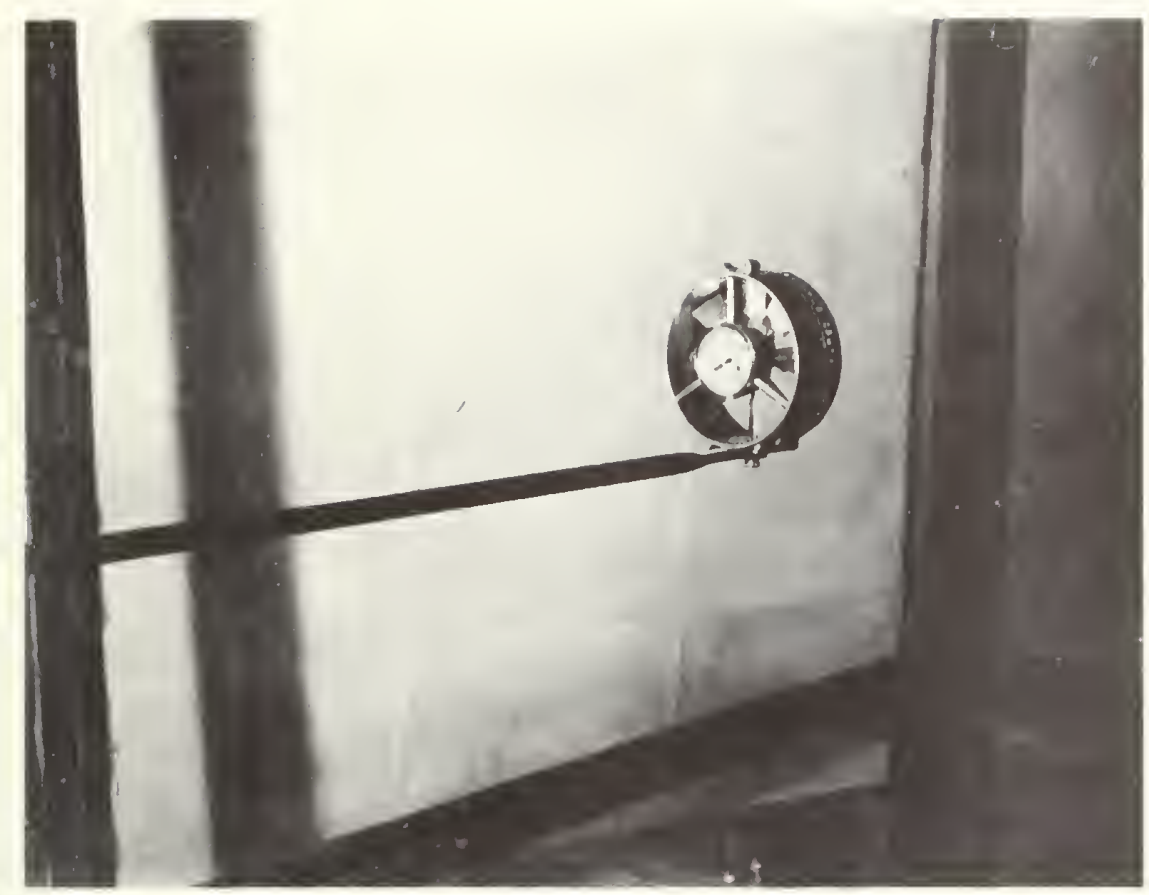

FIGURE 1. THE ANEMOMETER MOUNTED IN THE TUNNEL. 


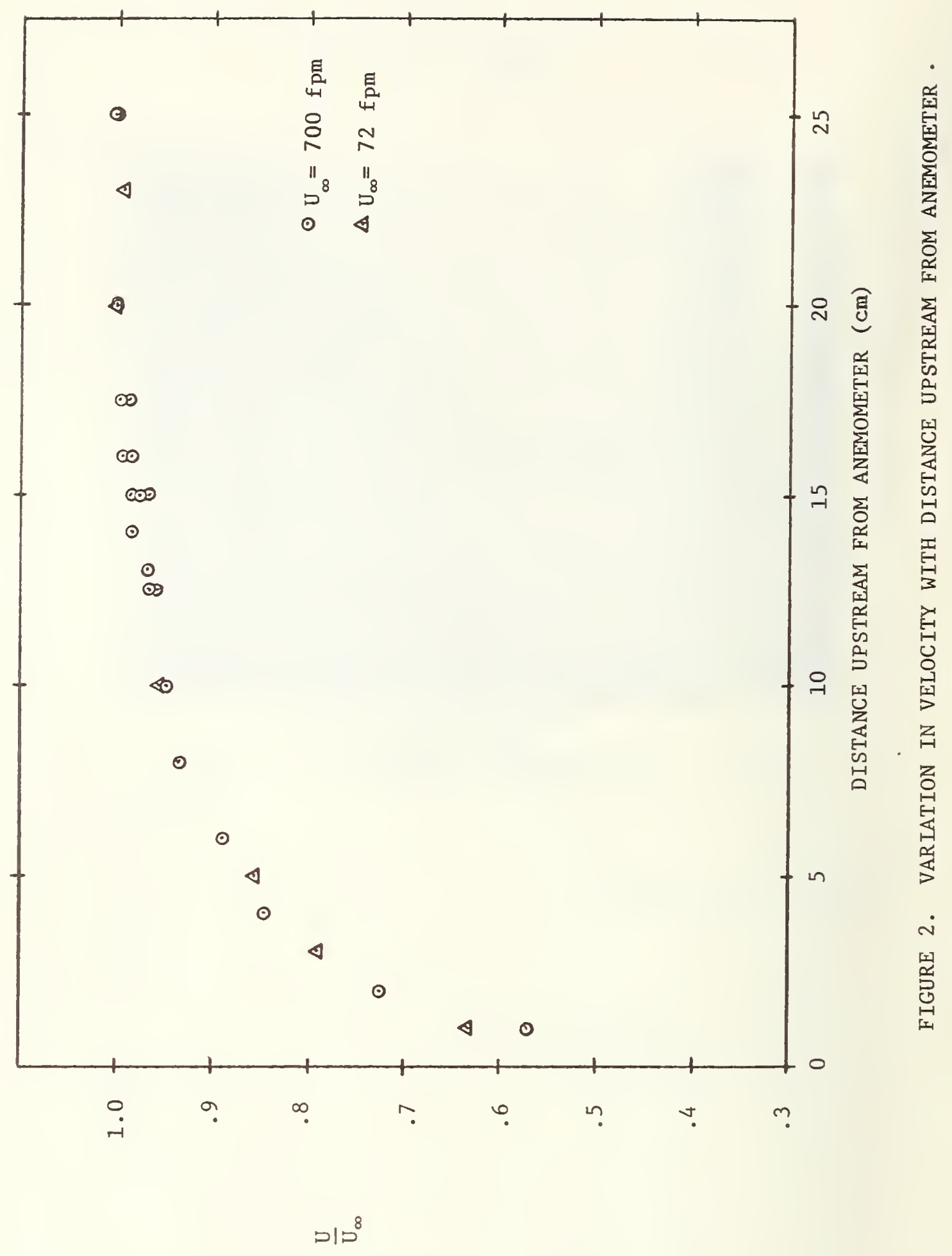




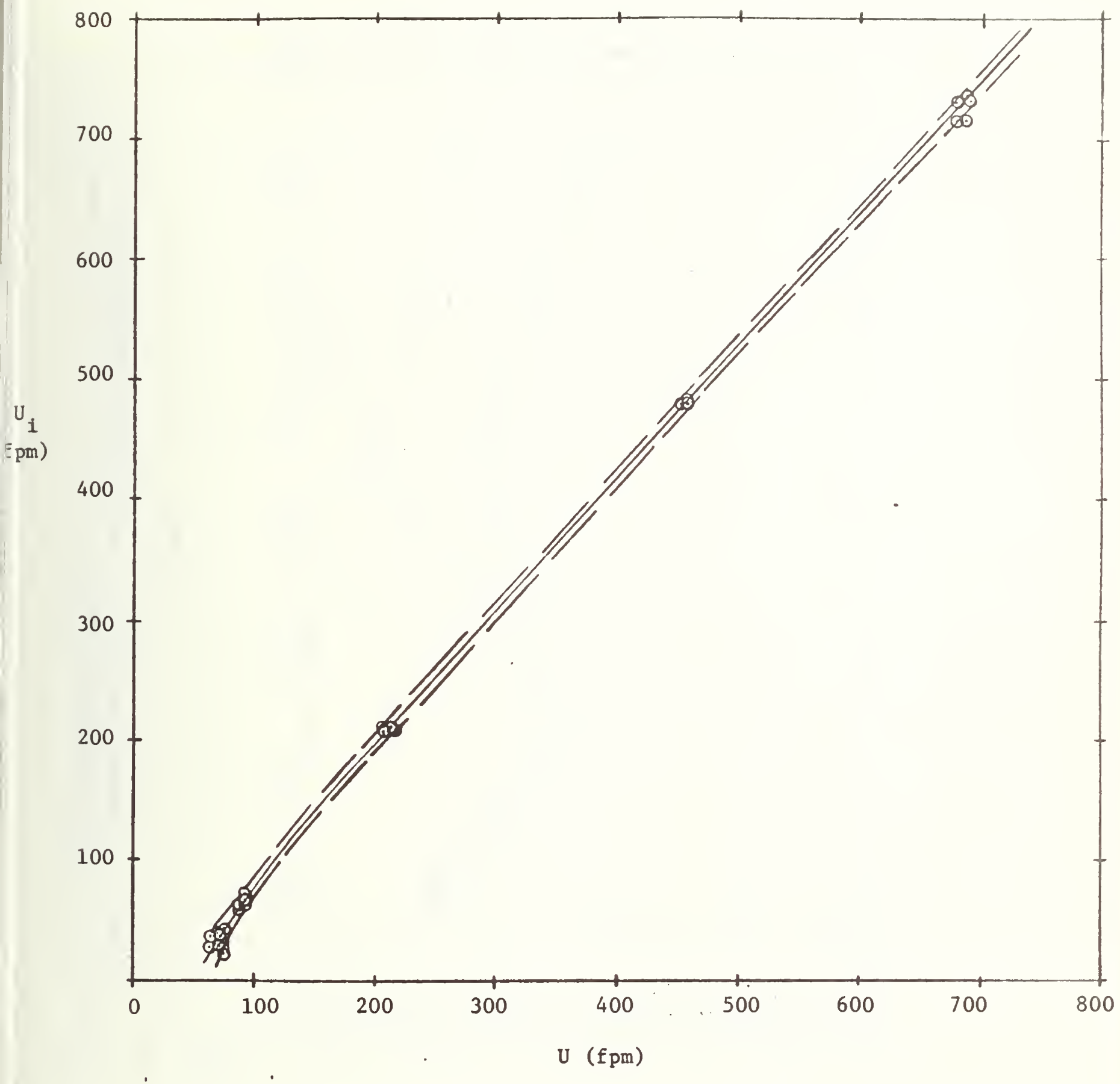

FIGURE 3. INDICATED VERSUS TRUE VELOCITY WITH $\pm 2 \sigma$ CURVES. 


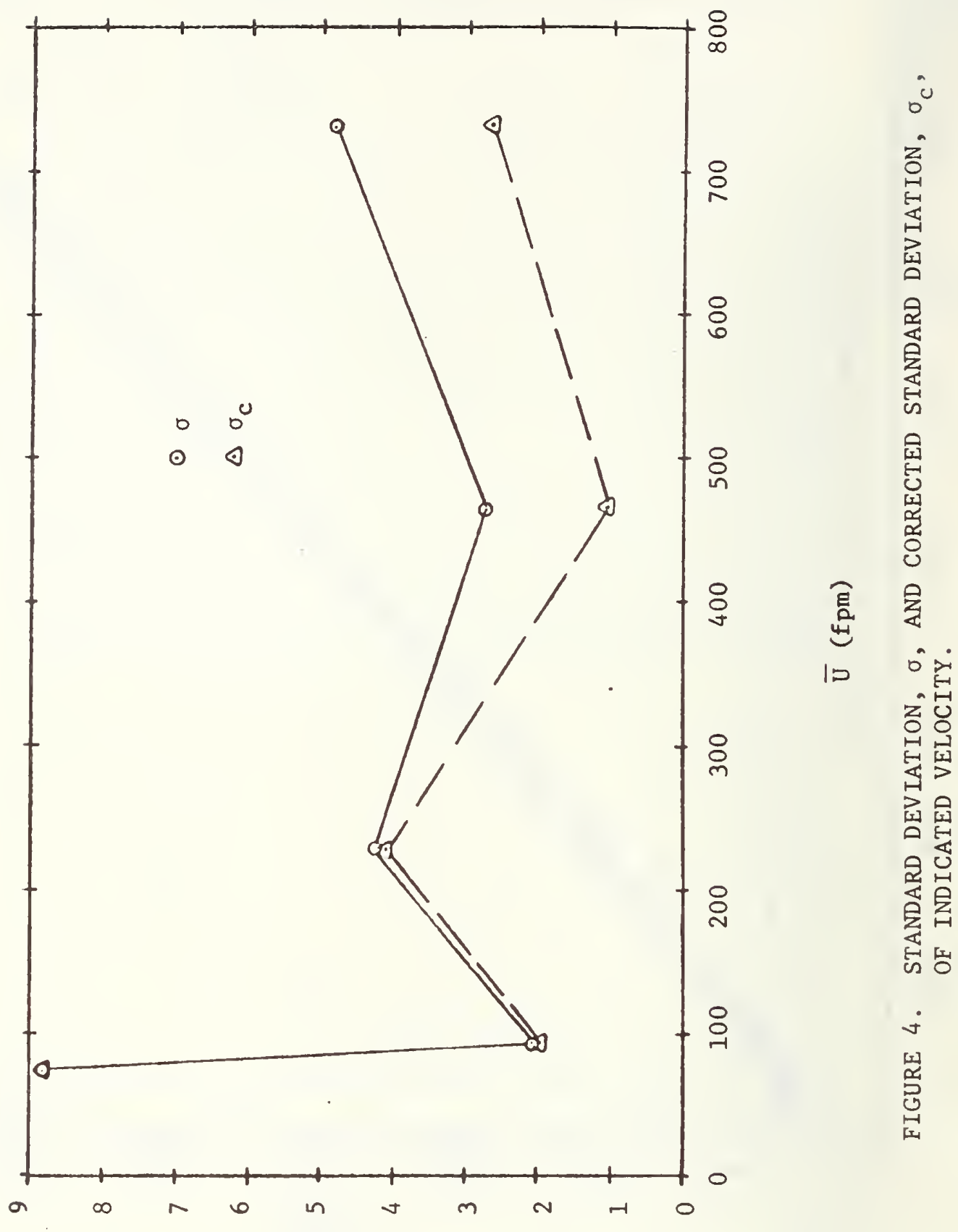

量 


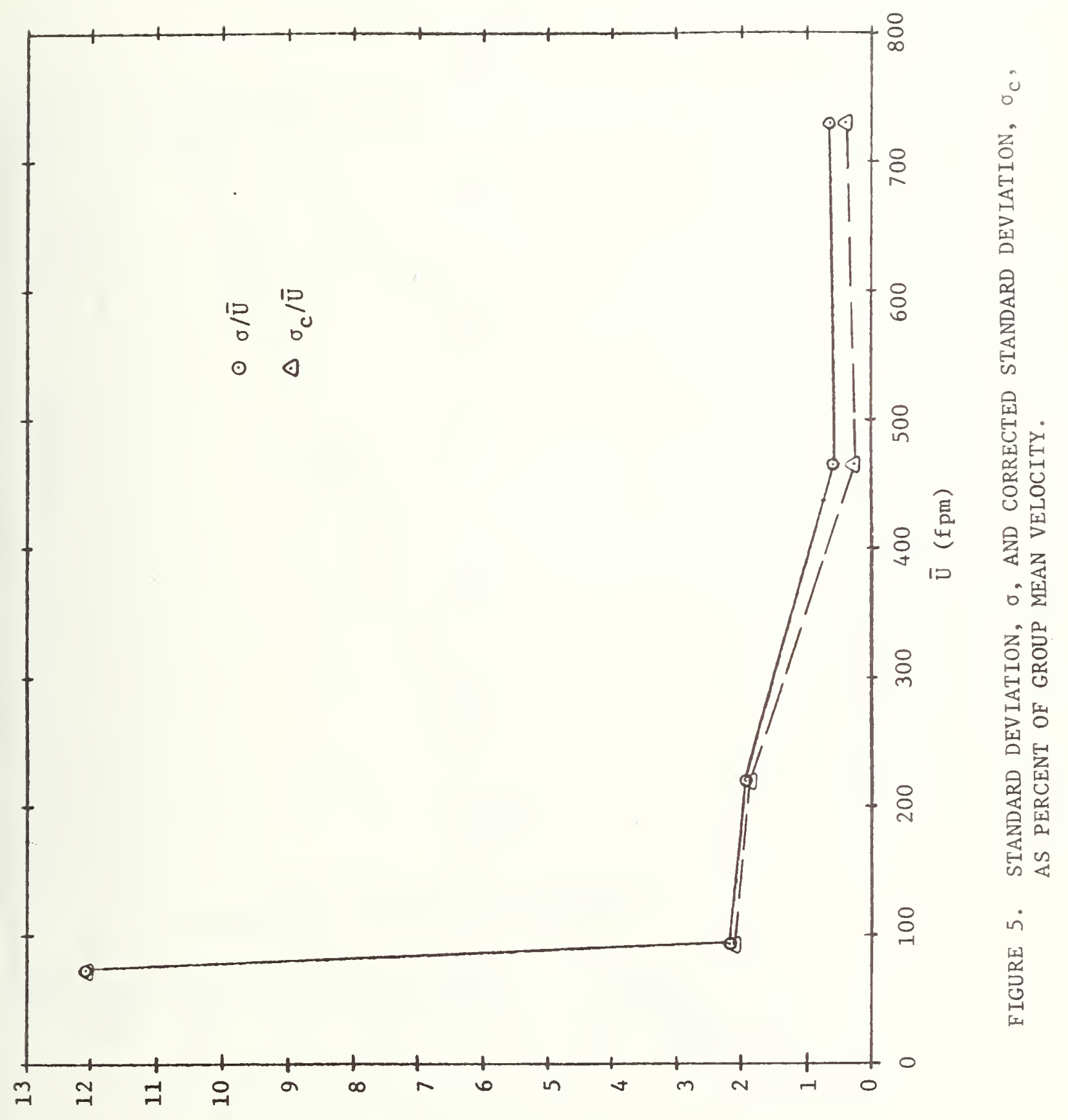

טוp 


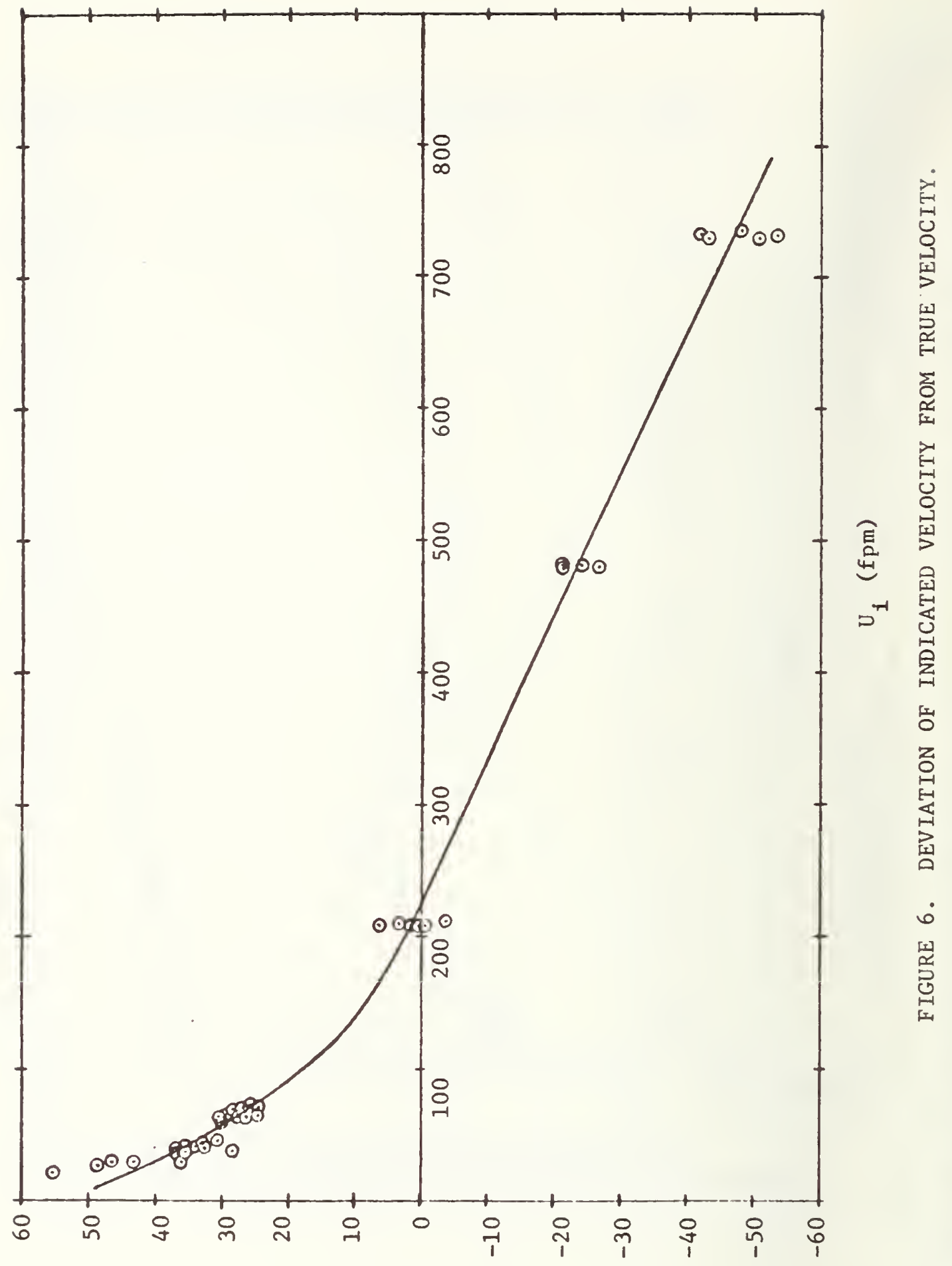

点重 


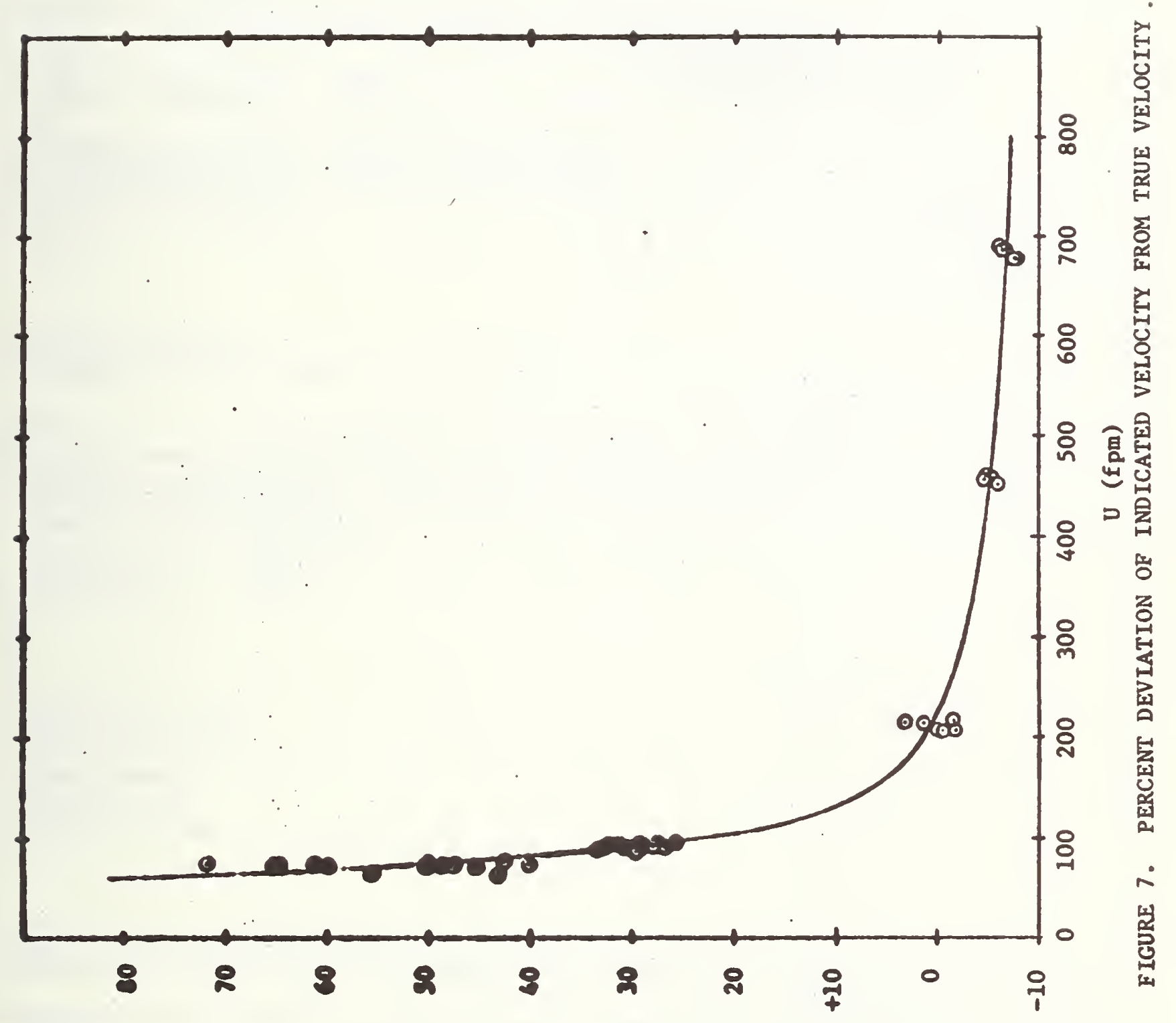

ริำ 
NBS.IIAA IHE $\vee, 1$, I

\begin{tabular}{|c|c|c|c|}
\hline $\begin{array}{l}\text { U.S. DEPT. OF COMM } \\
\text { BIBLIOGRAPHIC DATA } \\
\text { SHEET }\end{array}$ & 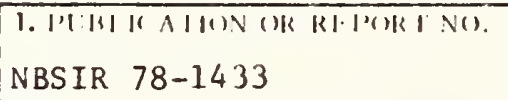 & $\begin{array}{l}\text { 2. (uov't Acension } \\
\text { No. }\end{array}$ & 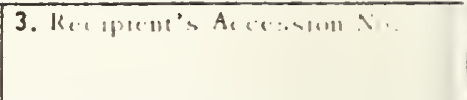 \\
\hline \multirow{2}{*}{\multicolumn{3}{|c|}{$\begin{array}{l}\text { 4. III1. ANI IIIIIII.I } \\
\text { LOW VELOCITY PERFORMANCE OF A BRONZE BEARING } \\
\text { VANE ANEMOMETER }\end{array}$}} & \multirow{2}{*}{ 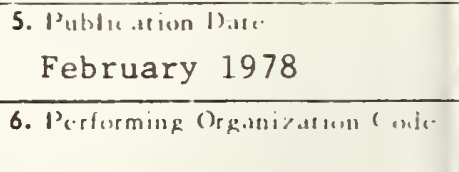 } \\
\hline & & & \\
\hline \multicolumn{3}{|c|}{$\begin{array}{l}\text { 7. Aufli()R(S) } \\
\text { L. P. Purtell }\end{array}$} & $\begin{array}{l}\text { 8. 'Perturning "'rkall. Repure No. } \\
\text { NBSIR 78-1433 }\end{array}$ \\
\hline \multirow{2}{*}{\multicolumn{2}{|c|}{$\begin{array}{l}\text { 9. I'FRIORMINC, OR(IANI\%ATION NAML ANI) AIMIRIISS } \\
\text { NATIONAL BUREAU OF STANDARDS } \\
\text { DEPARTMENT OF COMMERCE } \\
\text { WASHINGTON, D.C. } 20234\end{array}$}} & & 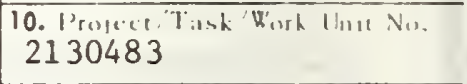 \\
\hline & & & $\begin{array}{l}\text { 11. I ontracticitant No. } \\
\text { H0166198 }\end{array}$ \\
\hline \multirow{2}{*}{\multicolumn{3}{|c|}{$\begin{array}{l}\text { 12. Sponsoring (Otganization Name and (omplete Address (Street, City, State, ZIP) } \\
\text { Office of the Assistant Director - Mining } \\
\text { Bureau of Mines } \\
\text { United States Department of the Interfor } \\
\text { Washington, D.C. } 20241\end{array}$}} & $\begin{array}{l}\text { 13. Pype of Report \& Perrod } \\
\text { Dec. } 1,1976 \text {-Feb. } 28,197\end{array}$ \\
\hline & & & 14. Sponsorimg Agency (ode \\
\hline
\end{tabular}

15. ST PPII:MENTARY NOTIS

16. AlSSTRAC I (A 200-word or less factual summary of most significant information. If document includes a significant bibliography or lilerature survey, mention it here.)

Performance of a bronze bearing vane anemometer is evaluated over the speed range of 64 to 690 feet per minute including starting speed and stopping speed. The tests were performed in the NBS Low Velocity Airflow Facility which provides a uniform flow of low turbulence and utilizes a laser velocimeter as the velocity standard.

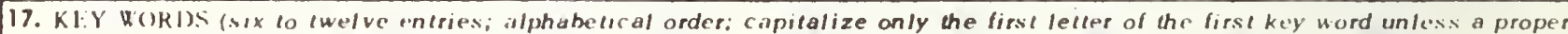
nume; separated by semicolons)

Airflow; anemometer; laser velocimeter; low velocity; performance; vane anemometer; wind tunnel.

18. ANAII.A1311.11Y

[xx Unlimited

For ()fficial Distribution. Do Not Release to NTIS

Ordet Prom Sup. of Duc., U.S. Ciovernment Printing Office

Washington, 1).( . 20,402, SD (at. No. C.13

Otder From National Technical Information Service (NTIS) Springfield, Virginia 22151

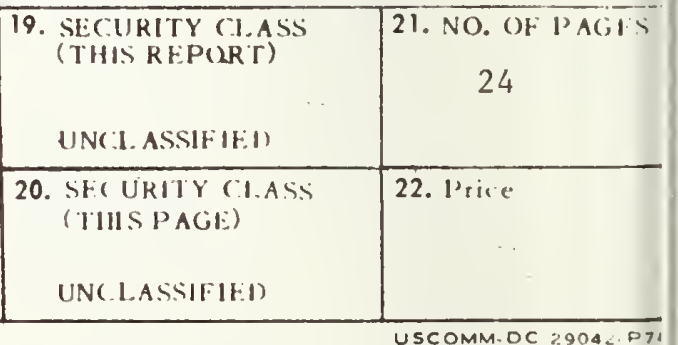


NBSIR 78-1434

\section{The Macroscopic Detection of Corrosion in Aluminum Aircraft Structures With Thermal Neutron Beams and Film Imaging Methods}

Report Prepared by

Donald A. Garrett

Reactor Radiation Division Institute for Materials Research National Bureau of Standards

Washington, D.C. 20234

Work Performed by

William Parker, Ph.D.

Martin Ganoczy

Michael Dorsey

Donald A. Garett

December 7, 1977

\section{A Report}

Submitted to the U.S. Naval Air

System Command, Washington, D.C.

USN Contract No. N00019-76-IP-69007 


\section{THE MACROSCOPIC DETECTION OF}

CORROSION IN ALUMINUM AIRCRAFT

STRUCTURES WITH THERMAL

NEUTRON BEAMS AND FILM

IMAGING METHODS

Report Prepared by

Donald A. Garrett

\section{Reactor Radiation Division}

Institute for Materials Research

National Bureau of Standards

Washington, D.C. 20234

Work Performed by

William Parker, Ph.D.

Martin Ganoczy

Michael Dorsey

Donald A. Garrett

December 7, 1977

A Report

Submitted to the U.S. Naval Air

System Command, Washington, D.C.

USN Contract No. N00019-76-IP-69007

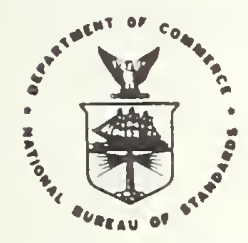

U.S. DEPARTMENT OF COMMERCE, Juanita M. Kreps, Secretary Dr. Sidney Harman. Under Secretary Jordan J. Baruch, Assistant Secretary for Science and Technology NATIONAL BUREAU OF STANDARDS. Ernest Ambler, Acting Director 

Abstract

1.0 Objectives

2.0 Background 2

3.0 Experimental Facilities at NBS 3

4.0 Experimental Procedures: General 3

$\begin{array}{lll}5.0 & \text { Technical Approach } & 6\end{array}$

6.0 Exposure Series 1 Through 3: General 6

6. 1-A Exposure Series IA 9

6.1-B Exposure Series 1B 12

6.1-C Exposure Series 1: Results and Conclusions 12

6.2-A Exposure Series 2A 15

6.2-B Exposure Series 2B 16

6.2-C Exposure Series 2: Results and Conclusions 21

6.3-A Exposure Series 3A 21

6.3-B Exposure Series 3B 22

6.3-C Exposure Series 3: Results and Conclusions 25

6.4-A Exposure Series 4

6.4-B Exposure Series 4: Results and Conclusions 29

7.0 Quantification of Corrosion 32

8.0 Remarks and Qualifications 32

$\begin{array}{lll}9.0 & \text { Summary } 33\end{array}$

10.0 Recommendations for Future Investigations at NBS 34

10.1 Converter Development 34

10.2 Real Time Imaging Methods for Corrosion Detection 35

10.3 Corrosion Quantification - Standard Penetrameter Development 36 

Table IA Exposure Series 1A: Radiographic Parameters

Table IB Exposure Series IB: Radiographic Parameters

Table 2A Exposure Series 2A: Radiographic Parameters

Table 2B Exposure Series 2B: Radiographic Parameters

Table 3A Exposure Series 3A: Radiographic Parameters

Table 3B Exposure Series 3B: Radiographic Parameters

Table 4 Exposure Series 4: Radiographic Parameters 



\section{Figures}

$\underline{\text { Page }}$

Fig. I Schematic Diagram of the NBS Thermal Neutron Radiography Facility

Fig. 2 C-2 Aircraft Vertical Fin Section 5

Fig. 3A Aluminum Corrosion Penetrameter $P-7$

Fig. 3B Aluminum Corrosion Penetrameter P-I - Close Up View 7

Fig. 4 Aluminum Corrosion Penetrameters $P-2-1$ through $P-2-4 \quad 8$

Fig. 5 Exposure Series IA: Radiographic Data 10-11

Fig. 6 Exposure Series 1B: Radiographic Data 13-14

Fig. 7 Exposure Series 2A: Radiographic Data 17-18

Fig. 8 Exposure Series 2B: Radiographic Data 19-20

Fig. 9 Exposure Series 3A: Radiographic Data 23-24

Fig. 10 Exposure Series 3B: Radiographic Data 26-27

Fig. 11 Exposure Series 4: Radiographic Data 30-31 


\section{Abstract}

The primary objective of this investigation was to determine the feasibility of detecting corrosion in aluminum Naval aircraft components with neutron radiographic interrogation and the use of standard corrosion penetrameters. Secondary objectives included the determination of the effect of object thickness on image quality, the defining of minimum levels of detectability and a preliminary investigation of a means whereby the degree of corrosion could be quantified with neutron radiographic data.

All objectives were met and may be summarized as follows:

Environment-induced corrosion can be detected with high sensitivity by thermal neutron radiographic interrogation, (2) the fluence at the image plane required to visualize corrosion with conventional imaging methods e.g., a gadolinium converter in conjunction with a medium contrast industrial $x$-ray film at density of 2.5 , is approximately $4 \times 10^{8} \mathrm{n}^{-\mathrm{cm}^{-2}}$. Assuming that a transportable neutron radiography system were capable of producing a flux of $1.5 \times 10^{4} \mathrm{n}-\mathrm{cm}^{-2}-\mathrm{sec}^{-1}$ at an $\mathrm{L} / \mathrm{D}$ ratio of $40: 1$, an exposure of 7.4 hours would be required, (3) at an L/D ratio of $40: 1$, the corrosion signatures of both surfaces of a thick object, e.g., a wing or airfoil, must be interrogated individually. This is due to the fact that geometrical unsharpness obliterates signature detail on the surface opposite the cassette. (4) The possibility of corrosion quantification does exist. This conclusion is based on an investigation with standard corrosion plaque penetrameters, and (5) although the use of ${ }^{6}$ LiF/ZnS light emitting converters is the most efficient method by which thermal neutron beams can be imaged, the results are inadequate for unambiguous signature analysis with presently available converters. 
1.0 Objectives

The primary objective of these investigations was to determine the feasibility of detecting corrosion in aluminum Naval aircraft components with neutron radiographic interrogation and the use of standard corrosion penetrameters. Secondary objectives included the determination of the effect of object thickness on corrosion image quality, the defining of minimum levels of detectability and a preliminary investigation of a means whereby the degree of corrosion could be quantified with neutron radiographic data.

\subsection{Background}

The nondestructive detection and visualization of environmentinduced corrosion in aircraft presents an important maintenance problem and economic impact in both the civilian and military sectors. Since there is no reliable instrumental method by which corrosion can be detected in inaccessible areas of aircraft structures, visual and destructive inspection methods must presently be employed.

Corrosion in aircraft generally is induced by the presence of moisture and oxygen. The corrosion products so generated oftentimes, but not always, contain hydrogen in the forms of hydrated oxides or hydroxides. In the case of salt-water induced corrosion, chlorine may also be present. Because of the high attenuation of thermal neutrons by hydrogen and chlorine, it should be possible to visualize corrosion areas using neutron radiographic interrogration.

The basic procedures governing the neutron radiographic inspection methods employed in these studies are outlined in this report. In addition, the results of preliminary experiments at the National Bureau 


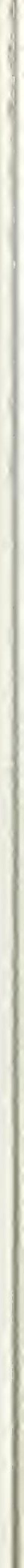


of Standards to establish minimum levels of corrosion detectability and proposed methods to quantify the degree of corrosion are presented.

\subsection{Experimental Facilities at the National Bureau of Standards}

The Thermal Neutron Radiography Facility (TNRF) at the NBS 10MW Research Reactor was employed for these investigations. At a power level of 10MW, the reactor provided a thermal neutron flux of $10^{7} \mathrm{n}-\mathrm{cm}^{-2}$ $-\mathrm{sec}^{-1}$ at the image $p l a n e$ for an L/D ratio of $40: 1$. The L/D ratio of the facility was variable from a minimum of 40:1 to a maximum of 500:1. The neutron beam is highly thermalized, having a gold-cadmium ratio of 500:1. During the course of these studies, the neutron beam shutter was manually operated. A schematic diagram of the facility is illustrated in Figure $T$.

\subsection{Experimental Procedures: General}

All radiographic data generated in these investigations was obtained using direct neutron imaging methods. Manual film development was performed throughout with Eastman Kodak standard industrial radiography chemistry. A 7 in.-thick section cut from an uncorroded C-2 aircraft vertical fin was used as a standard object to be radiographed. The fin, which was obtained from the NAVAIR Rework Facility at North Island, San Diego, CA is illustrated in Figure 2.

Standard corrosion penetrameters were fabricated from aircraftgrade aluminum which had been corroded under controlled environments for predetermined periods of time. The penetrameter samples were obtained from the Naval Air Development Center, Warminster, PA. Two types of penetrameters were employed in these investigations. 


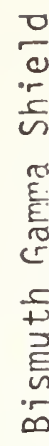
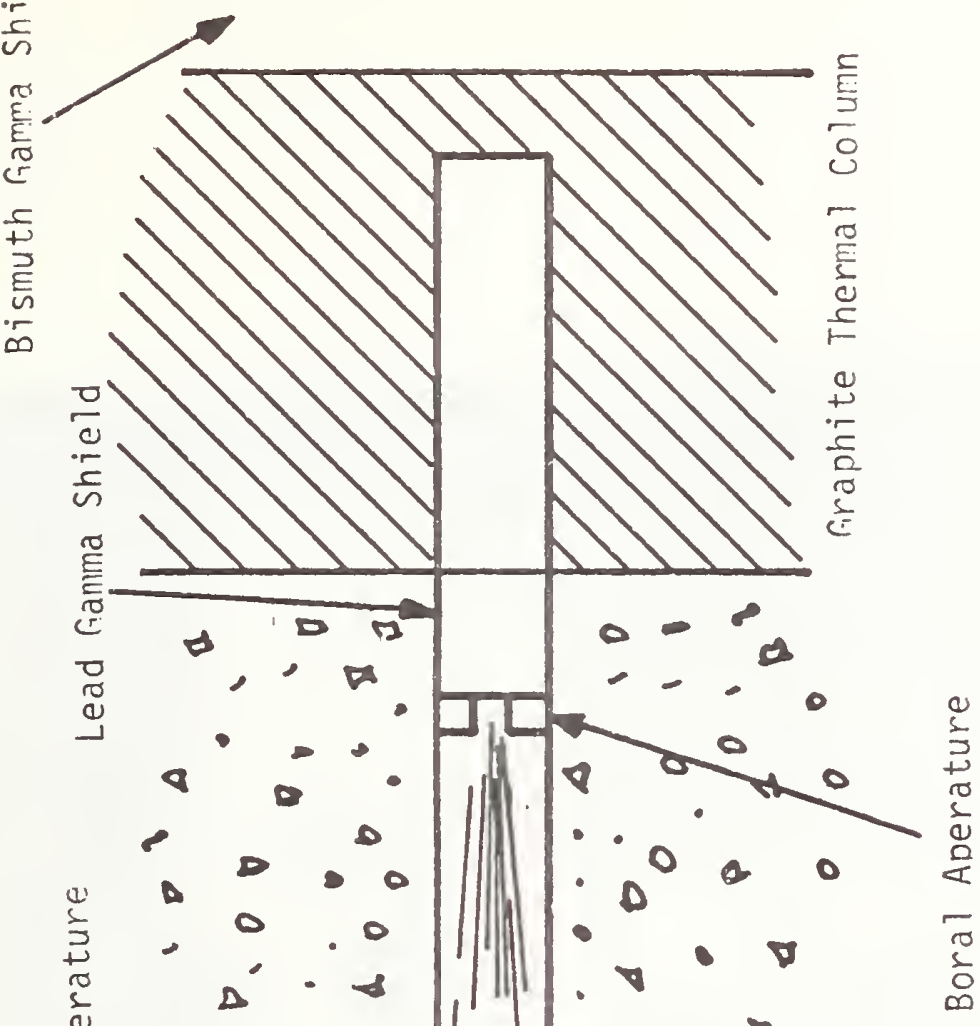

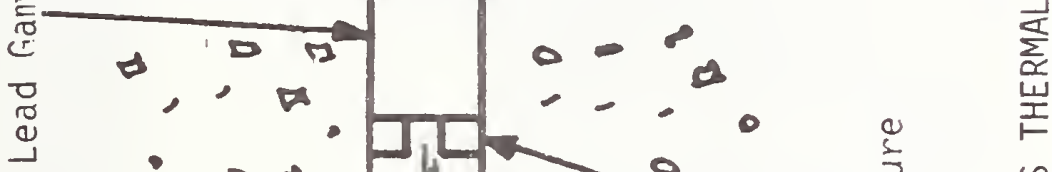

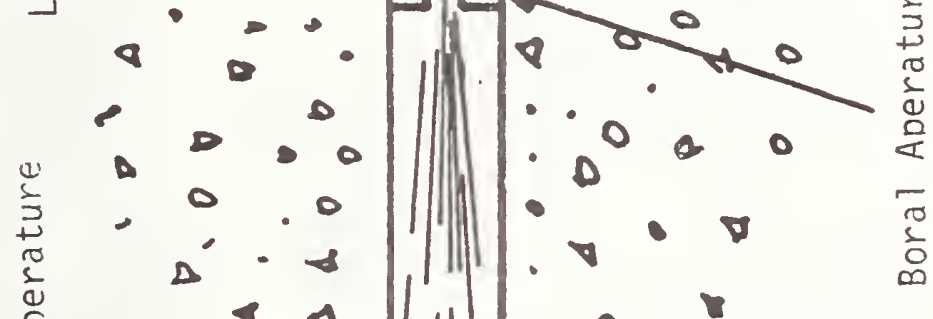

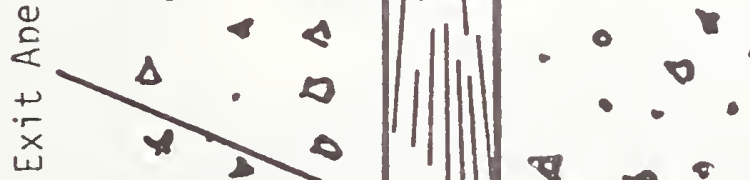

$\nabla \infty \sigma$

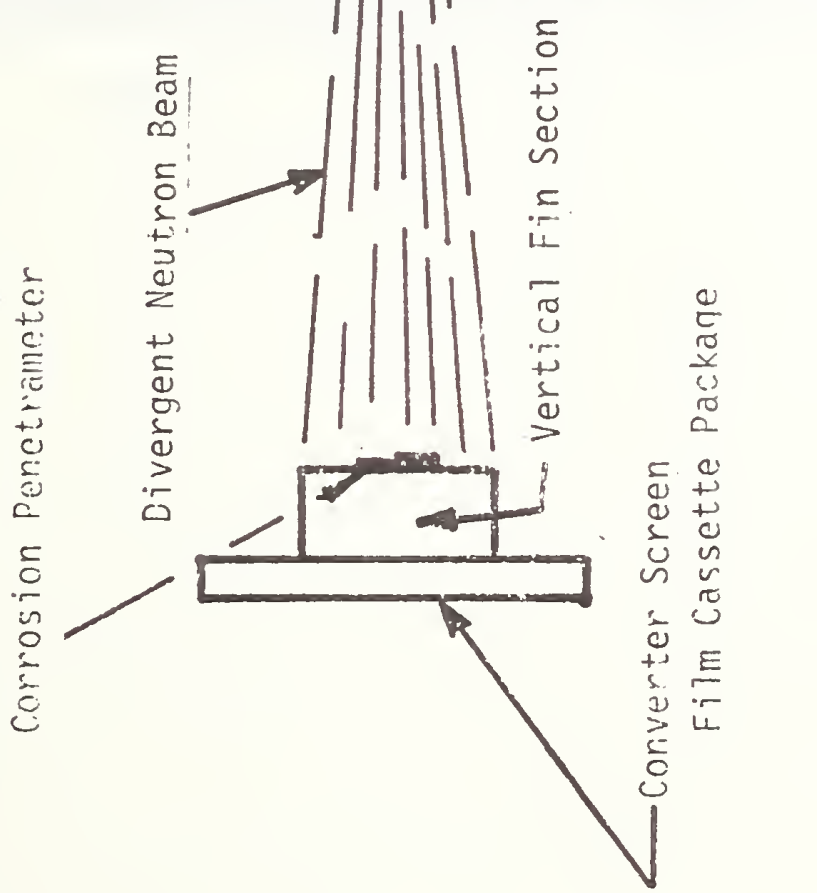

穵口

峲

山

능

这品

造它

등

$\cup \frac{1}{\alpha}$

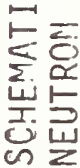

$-$

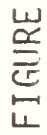




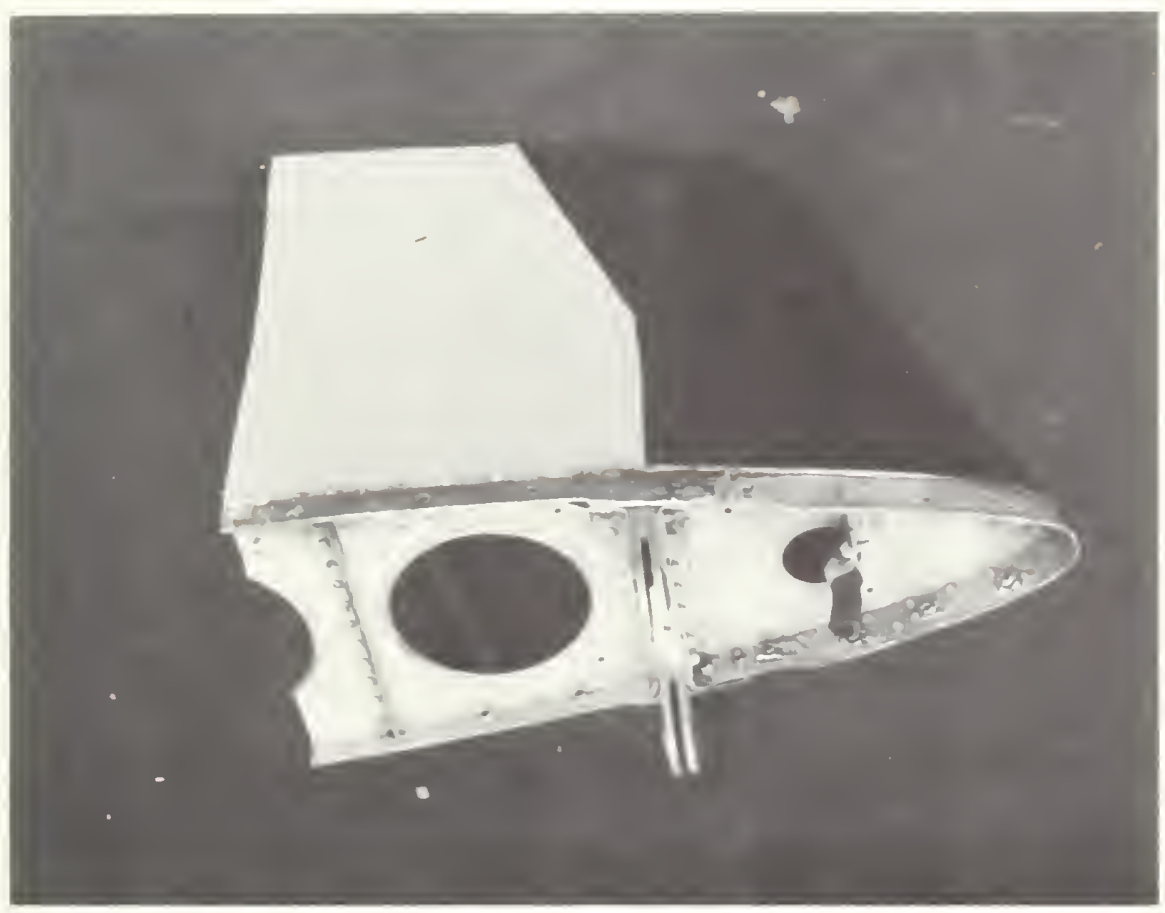

FIGURE 2. C-2 VERTICAL AIRFOIL 
The first was fabricated from aircraft-grade aluminum which had been subjected to a super-saturated salt water spray for $6.5 \mathrm{hrs}$. Nominal step thicknesses were $0.125 \mathrm{in}$. and $0.87 \mathrm{in}$. Two views of this penetrameter are illustrated in Figures $3 A$ and 38 . This penetrameter will be referred to as $P-1$ in this report.

The second set of four penetrameters was fabricated from 0.062 in.thick aircraft-grade aluminum plates which had been subjected to a salt water spray/ $/ \mathrm{SO}_{2}$ gas environment for zero, four, eight and fifteen days. This set which will be referred to as $P-2-1$ through $P-2-4$ in this report, is illustrated in Figure 4. No effort was made to correlate the corrosion penetrameters with real life conditions. They were employed only to provide corrosion under standardized conditions.

\subsection{Technical Approach}

The tasks outlined in the program objectives were divided into four systematic experiments, each with one or more objectives. The objectives of each exposure series at the radiographic parameters employed, and the experimental results are illustrated.

\subsection{Exposure Series 1 Through 3: General}

The general objectives of this series of exposures were:

(1) To determine the feasibility of utilizing neutron radiographic techniques to visualize corrosion areas in aircraft-grade aluminum employing several thermal neutron film-converter imaging techniques and a standard corrosion penetrameter.

(2) To assess the effect of object thickness on the penetrameter image quality.

(3) To observe the effect of analog edge enhancement on the penetrameter image quality. 



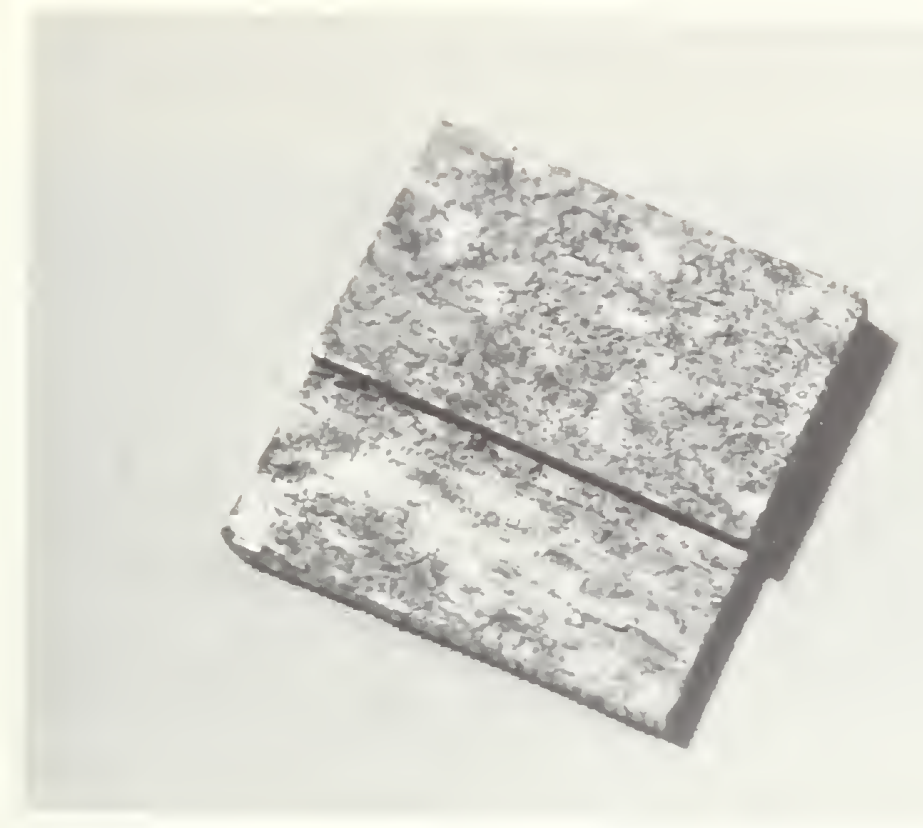

FIGURE 3A. ALUMINUM CORROSION PENETRAMETER

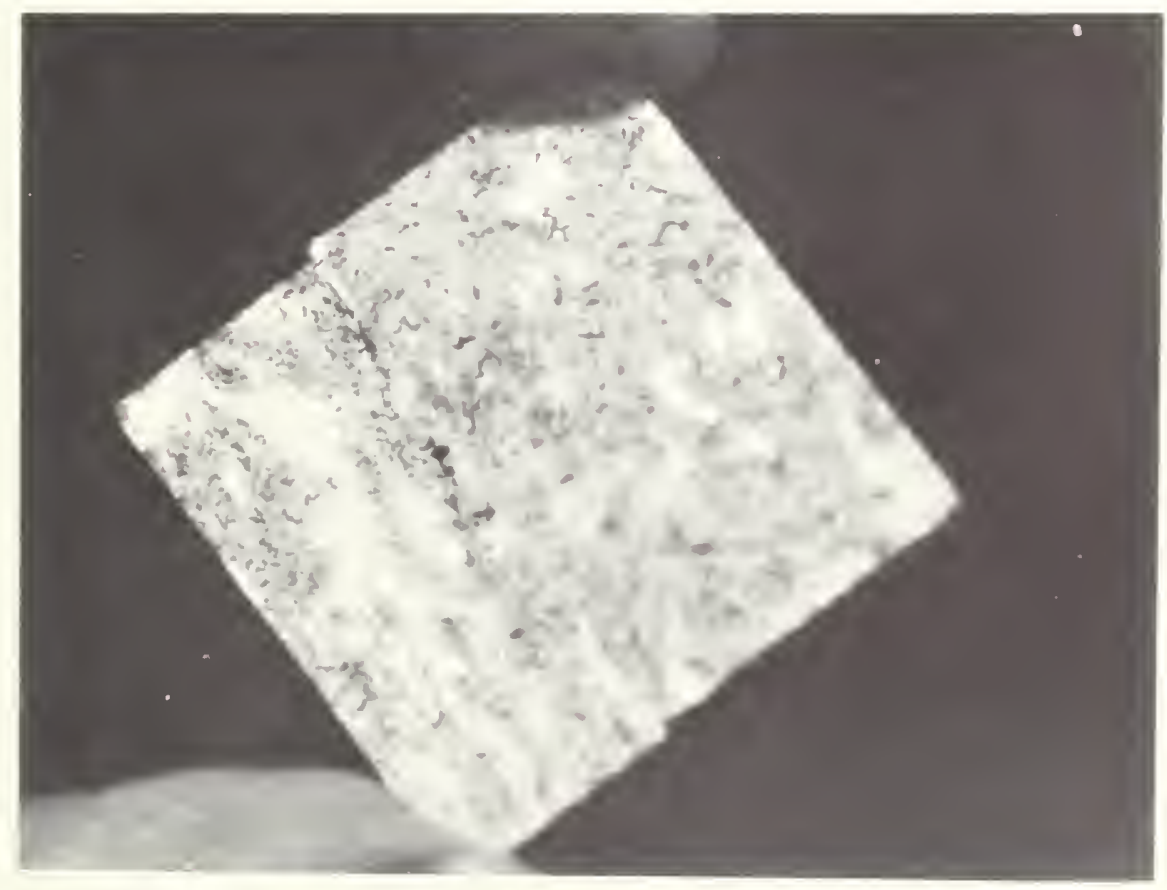

FIGURE 3B. ALUMINUM CORROSION PENETRAMETER CLOSE-UP VIEW 


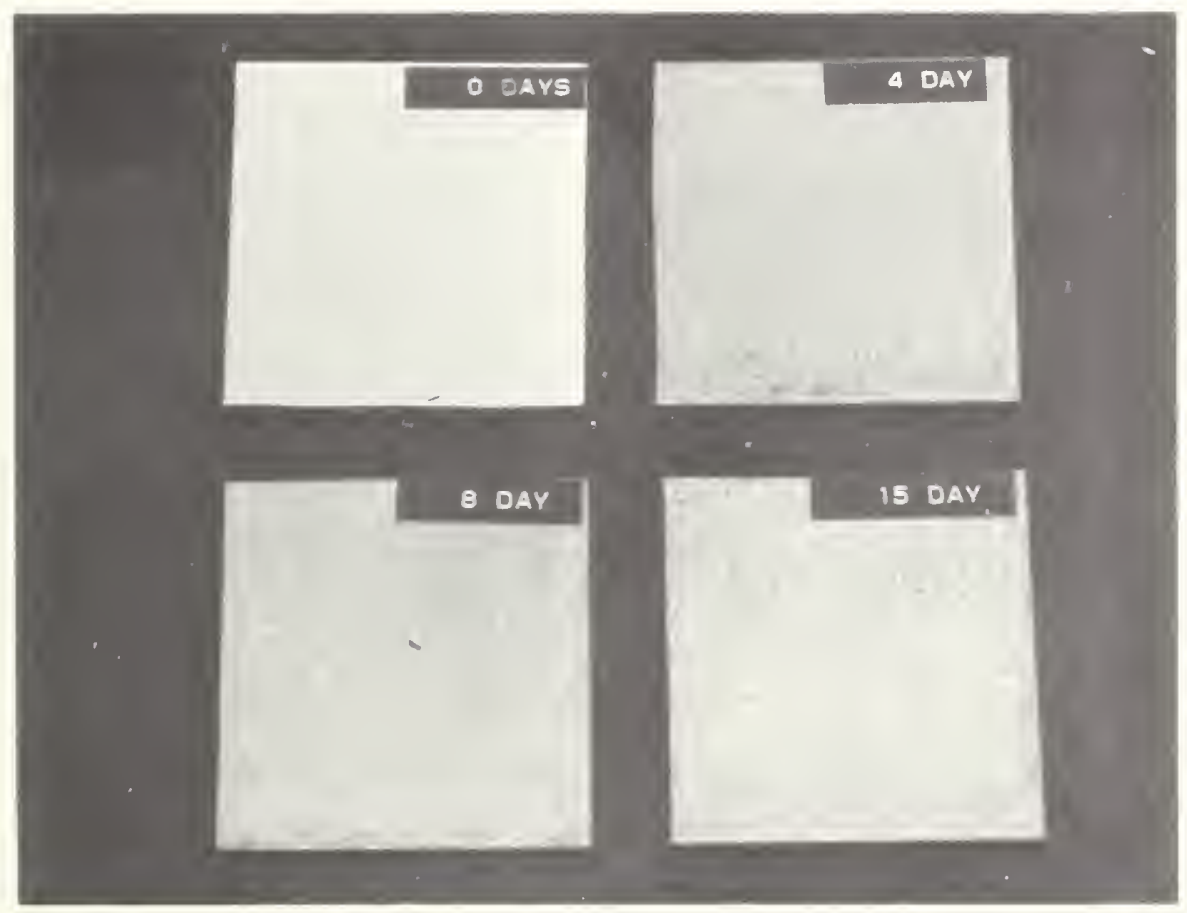

FIGURE 4. ALUMINUM CORPOSION PENETRAMETERS P-2-1 THROUGH P-2-4 

In exposure Series 1 through 3, the penetrameter, object and geometry outlined below are identical, only the radiographic parameters are changed in each series. Radiographic exposures were made of:
(A) The penetrameter $\mathrm{P}-1$ alone.
(B) The $C-2$ vertical fin section alone.
(C) The $C-2$ vertical fin section with penetrameter $P-1$ facing the cassette.
(D) The $C-2$ vertical fin with the penetrameter $P-1$ facing the collimated neutron source.
(E) Analog edge enhanced image of $C$ above.
(F) Analog edge enhanced image of $D$ above.

\section{1-A Exposure Series IA}

The radiographic parameters employed in the Exposure Series IA are outlined in Table IA below. This series of exposures serves to illustrate the radiographic data obtained utilizing a reactor-based system having a high (200:1) L/D ratio and employing medium-contrast (Kodak Type M) film. The radiographic data are illustrated in figures $5 \mathrm{~A}$ through $5 \mathrm{~F}$.

Table 1A: Exposure Series 1A: Radiographic Parameters
Converter
0.0005 in. Vapor Deposited Gd
Film Type
Kodak Type M
L/D Ratio
200:1
Exposure Time/Fluence
$50 \mathrm{~min} .16 \times 10^{8} \mathrm{n}-\mathrm{cm}^{-2}$
Neutron Beam Cd Ratio
500:1
Penetrameter
$p-1$
object
C-2 Vertical Fin Section 

Fig. 5: Exposure Series 1A: Radiographic Data

PENETRAMETER

(A)

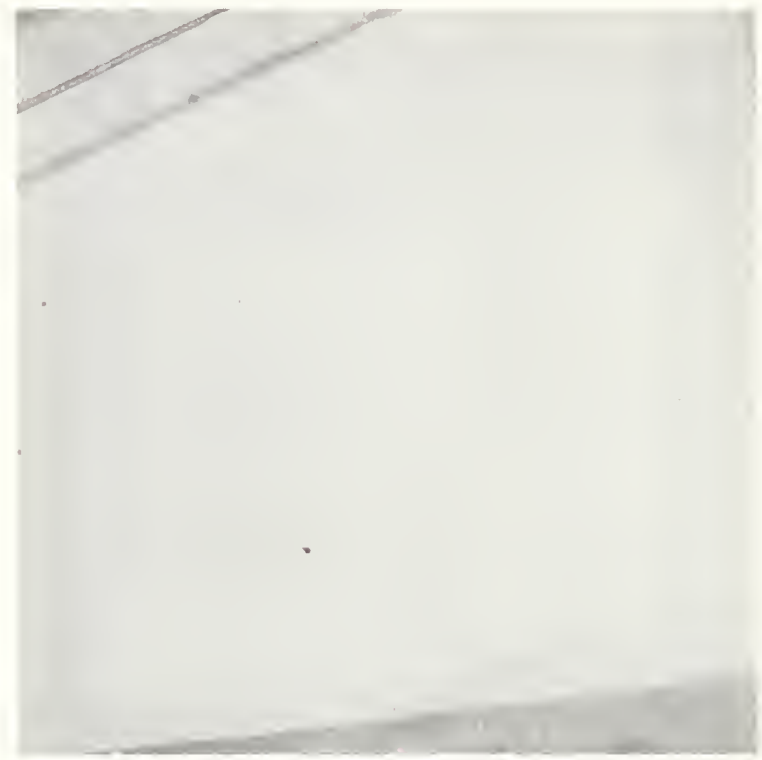

$\because \approx 2$ VERTICAL FIN

(B)
C-2 VERTICAL FIN PENETRAMETER FACING CASJETTE

(C)
C-2 VERTICAL FIN PENETRAMETER FACING SOUREE

(D) 
Fig. 5: Continued

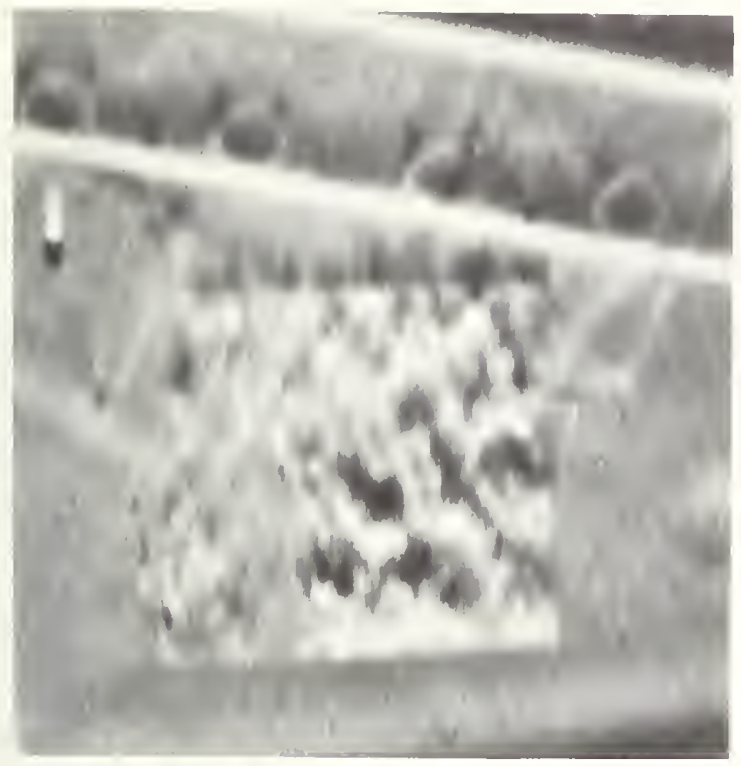

ANALOG EDGE ENHANCEMENT PENETRANETER FACING CASSETTE

(E)

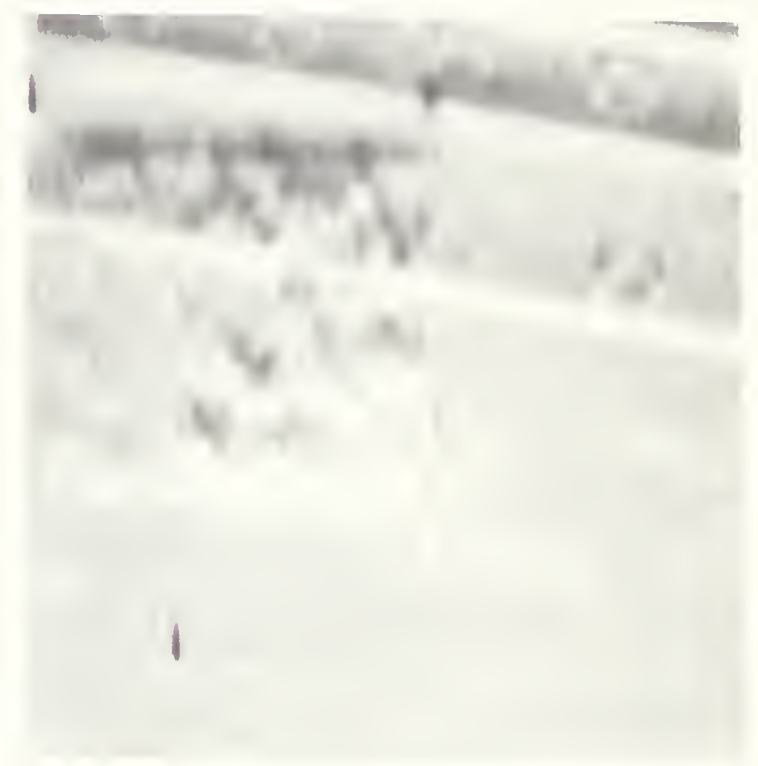

ANALOG EDSE ENTLNCEMENT PENEIKRMTRR EALING SOURCE

(F) 


\section{1-B Exposure Series 1B}

The objective of this series of exposures was to determine the effect on the penetrameter image quality when the L/D ratio was reduced from 200:1 to 43:1. These experiments provided comparative data of the results obtainable with a reactor-based system having a high L/D ratio to a source-based system having a low L/D ratio.

Radiographic parameters employed in Exposure Series IB are outlined in Table 18 below.

Table 1B: Exposure Series 1B: Radiographic Parameters

Converter

Film Type

L/D Ratio

Exposure Time/Fluence

Neutron Beam Cd Ratio

Penetrameter

object
0.0005 in. Vapor Deposited Gd

Kodak Type M

43:1

$90 \mathrm{sec} . / 4 \times 10^{8} \mathrm{n}-\mathrm{cm}^{-2}$

500: 1

$\mathrm{P}-1$

C-2 Vertical Fin Section

The radiographic data derived from Exposure Series $1 B$ are illustrated in Figures $6 \mathrm{~A}$ through $6 \mathrm{~F}$.

(1) Significant Parameter Change

6. 1-C Exposure Series: Results and Conclusions

(a) Salt water induced corrosion signatures in aircraft-grade aluminum can be visualized with neutron radiography using a 200:1 L/D ratio. The effect of the $7 \mathrm{in}$-thick fin thickness is to degrade the image quality. However, the signature can still be discerned as illustrated in Figures $5 \mathrm{C}$ and $5 \mathrm{D}$. 
Fiq. 6: Exposure Series 1B: Radiogranhic Data

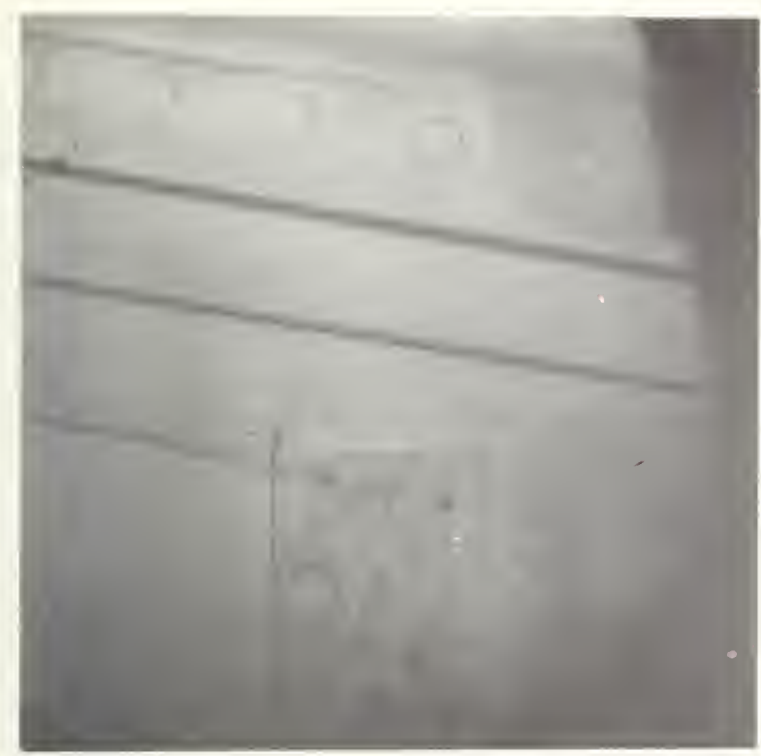

PENETRAMETER

(A)

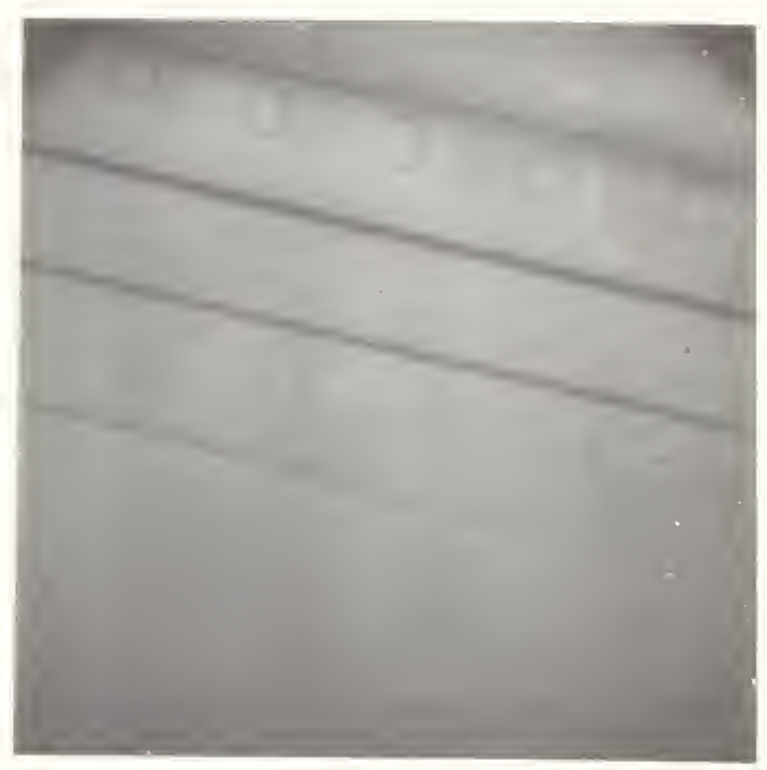

C-2 VERTICAL FIN

(B)

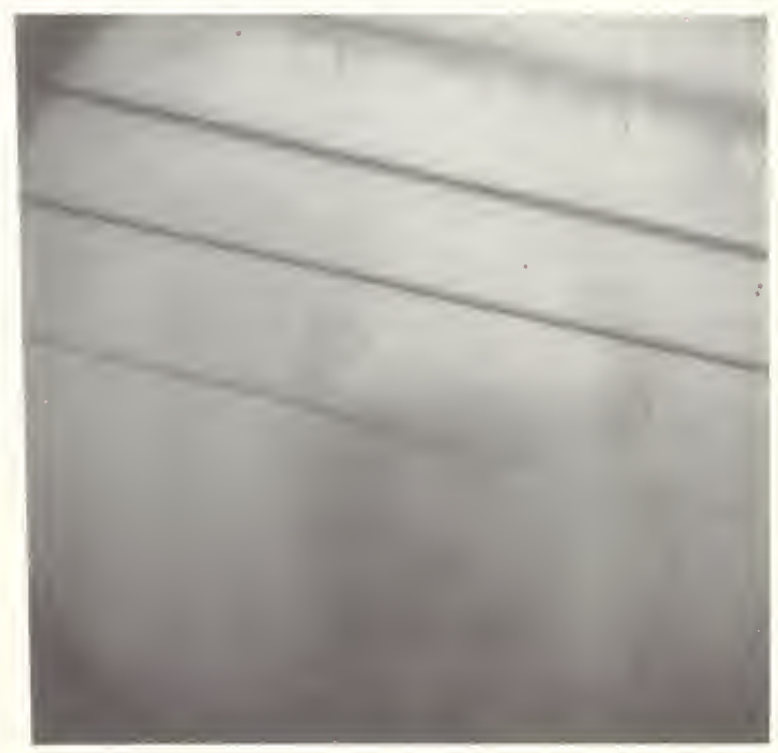

C-2 VERTICAL FIM PENETRAMETER FACING SOURCE

(D) 
Fiq. 6: Continued

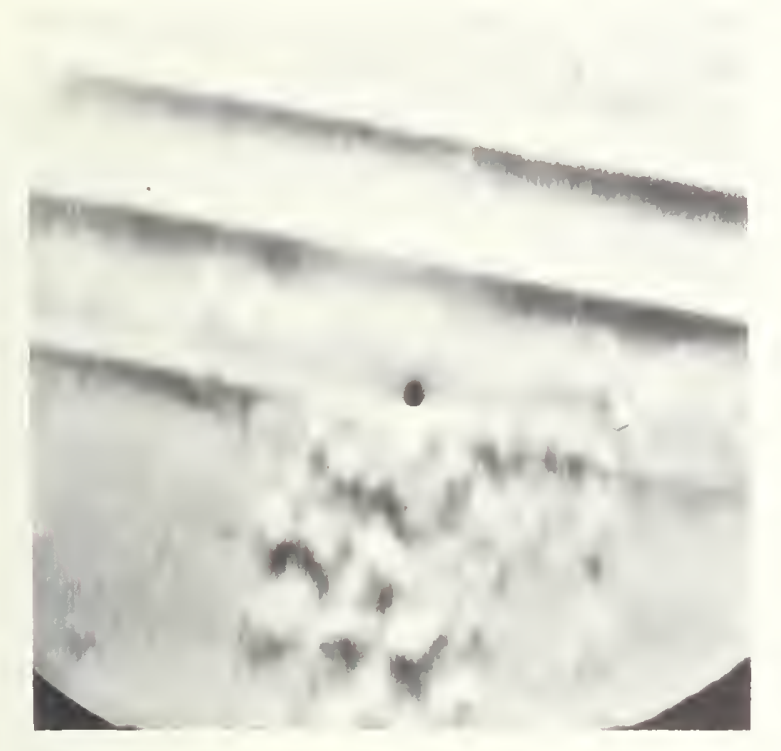

ANALOG EDGE ENHANCENENT PENETRAMETER FACING CASSETTE

(E)

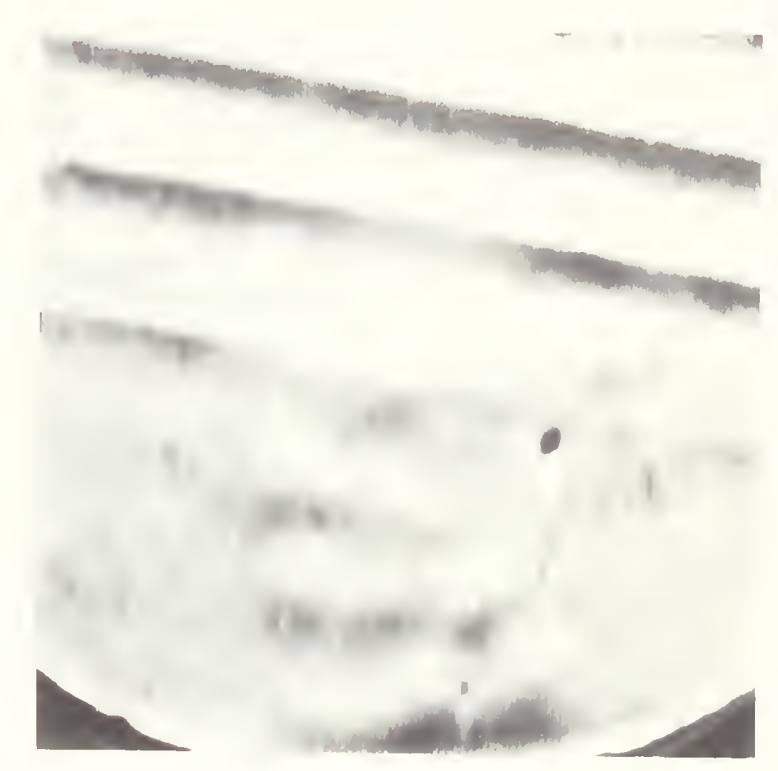

ANALOG EDGE ENHANCEMENT PENETRAMETER FACING SOURCE

(F) 
(b) The time required for the exposure was $50 \mathrm{~min}$. for a L/D ratio of 200:1.

(c) With the penetrameter on either side of the fin, analog edge enhancement aids in identifying the corrosion signature.

(d) When the L/D ratio is reduced to that of a field system, e.g., 43:1, The corrosion signature can only be visualized when the penetrameter was placed on the cassette side of the fin as shown in Figures $6 C$ and $6 D$, making it necessary to inspect each side of an airfoil of 7 in. thickness individually.

(e) The time required for the exposure was $90 \mathrm{sec}$. for a L/D ratio of $43: 1$.

(f) With a L/D ratio of $43: 1$, image edge enhancement aids in visualizing the corrosion penetrameter when placed on the source side of the film, however, paint could possibly produce a similar signature.

\section{2-A Exposure Series 2A}

In the group 2 series of exposures the 0.0005 in.-thick Gd converter has been replaced by a $\mathrm{Gd}_{2} \mathrm{O}_{2} \mathrm{~S}$ converter. The radiographic parameters employed in this series of exposures is given in Table $2 \mathrm{~A}$ below. 
Table 2A: Exposure Series 2A: Radiographic Parameters

Converter

Film Type

L/D Ratio

Exposure Time/Fluence

Neutron Beam Cd Ratio

Penetrameter

object
$\mathrm{Gd}_{2} \mathrm{O}_{2} \mathrm{~S}$

Kodak Type $M$

200: 1

$15 \mathrm{~min} . / 2 \times 10^{8} \mathrm{n}-\mathrm{cm}^{-2}$

500:1

$\mathrm{P}-1$

C-2 Vertical Fin

The radiographic data resulting from exposure series $2 A$ are illustrated in Figures $7 \mathrm{~A}$ through $7 \mathrm{~F}$.

(2) Significant Parameter Change

\section{2-B Exposure Series 2B}

The objective of Exposure $2 \mathrm{~B}$ was to examine the radiographic penetrameter $P-1$ using a $G_{2}{ }_{2}{ }_{2} S$ converter, when the $L / D$ ratio was reduced from 200:1 to 43:1. The radiographic parameters employed in this exposure series are outlined in Table $2 B$ below.

Table 2B: Exposure Series 2B: Radiographic Parameters

Converter

Film Type

L/D Ratio

Exposure Time/Fluence

Neutron Beam Cd Ratio

Penetrameter

Object
$\mathrm{Gd}_{2} \mathrm{O}_{2} \mathrm{~S}$

Kodak Type $M$

43: 1

(3)

$45 \mathrm{sec} . / 2 \times 10^{8} \mathrm{n}-\mathrm{cm}^{-2}$

500: 1

$\mathrm{P}-1$

C-2 Vertical Fin Section

The radiographic data from this exposure series are illustrated in Figures $8 \mathrm{~A}$ through $8 \mathrm{~F}$.

(3) Significant Parameter Changes 
Fig. 7: Exposure Series 2A: Radiogranhic Data

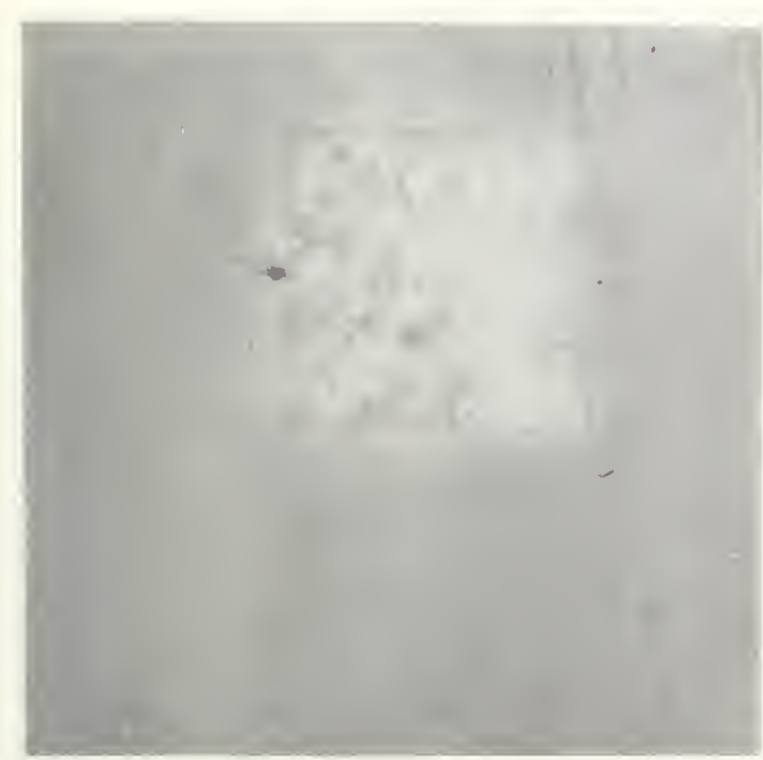

PENETRAMETER

(A)

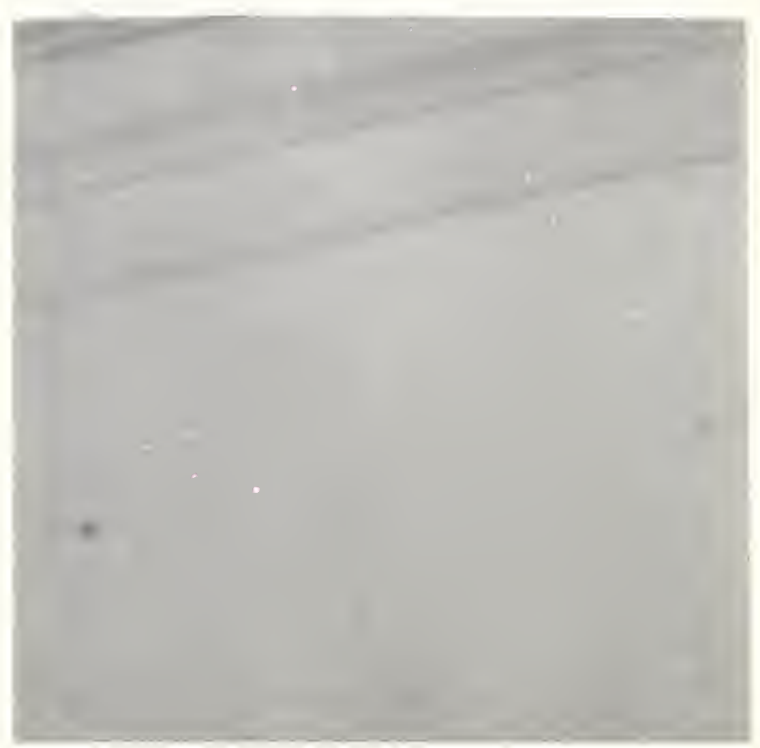

C-2 VERTICAL FIN

(B)
C-2 VERTICAL FIN

PENETRAMMETER FACING CASSETTE

(C)
C-2 VERTICAL FIN PENETRAMETER FACING SOURCE

(D) 

Fig. 7: Continued

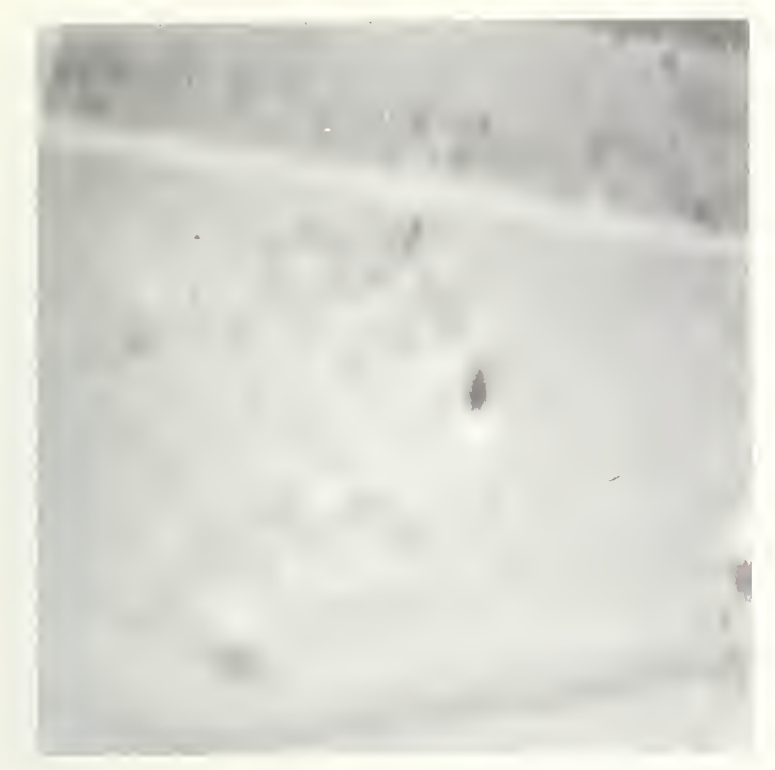

ANALOG EDGE ENHANCEMENT PENETRAMETER FACING CASSETTE.

(E)

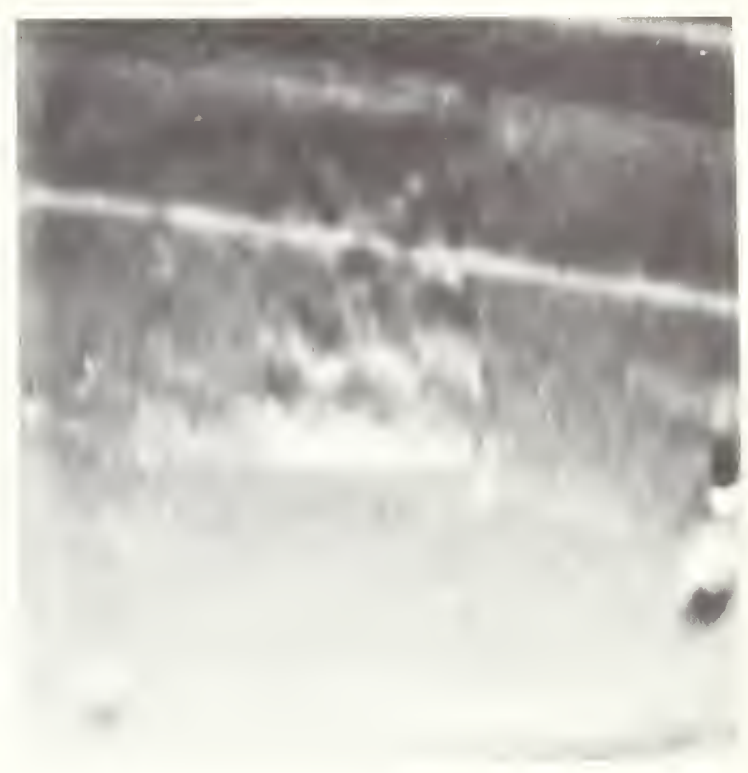

ANALOG EDGE ENHANCEMENT PENETRANETER FACING SOURCE

( $F)$ 
Fig. 8: Exposure Series 2B: Radiogranhic Data

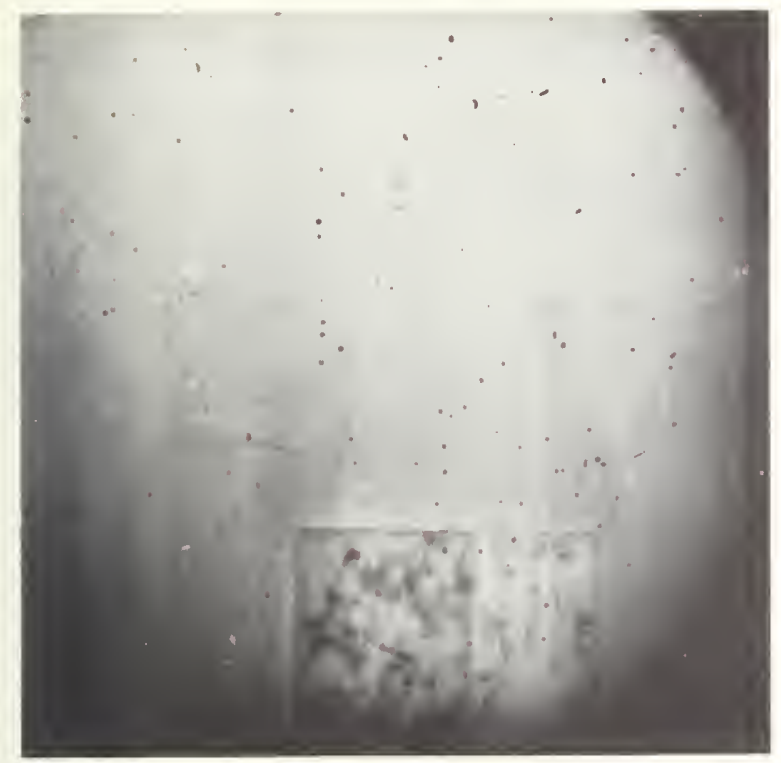

PENETRAMETER

(A)

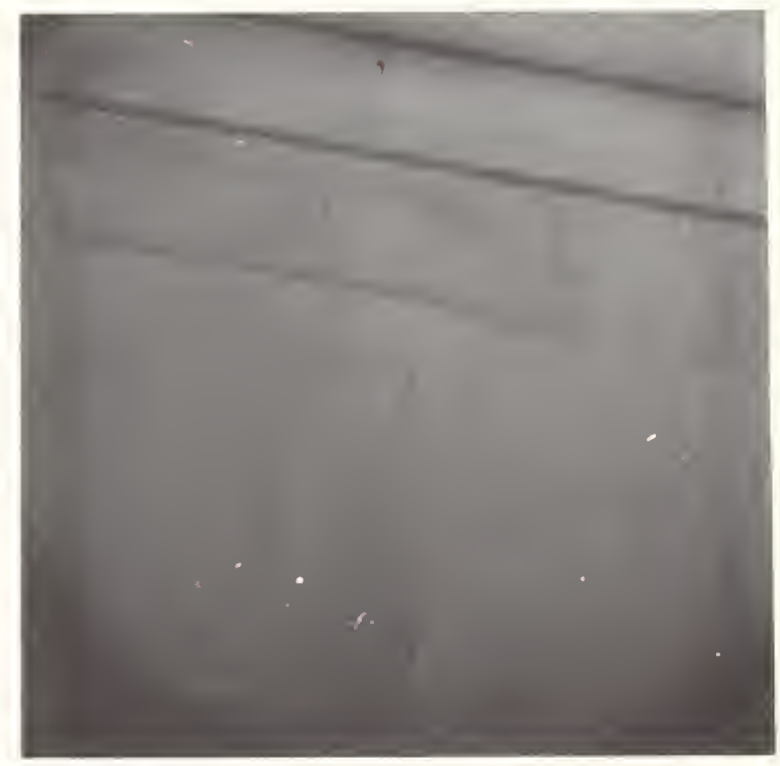

C-2 VERTICAL FIN

(B)

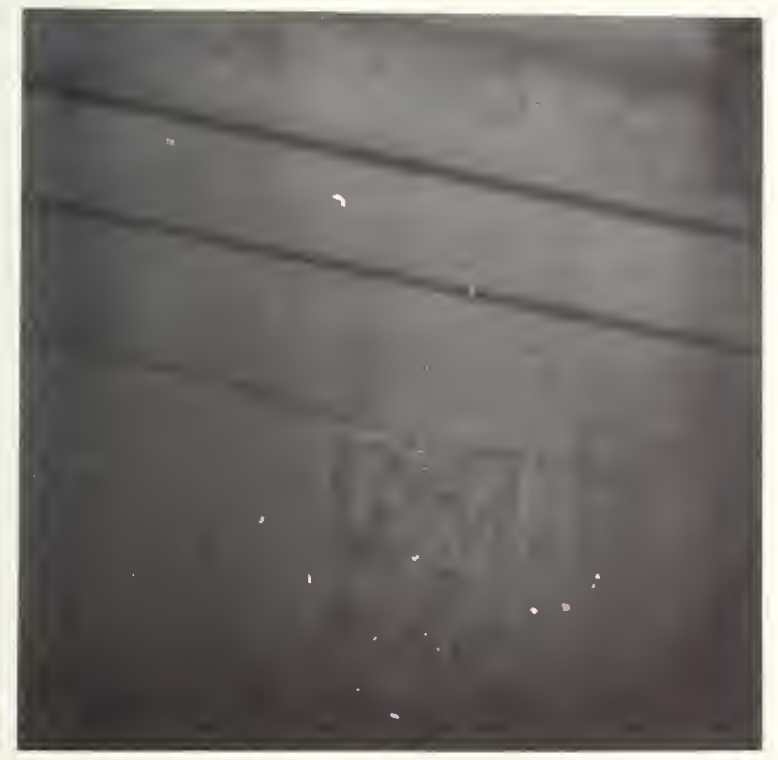

C-2 VERTICAL FIN

PENETRAMETER FACING CASSETTE

(C)

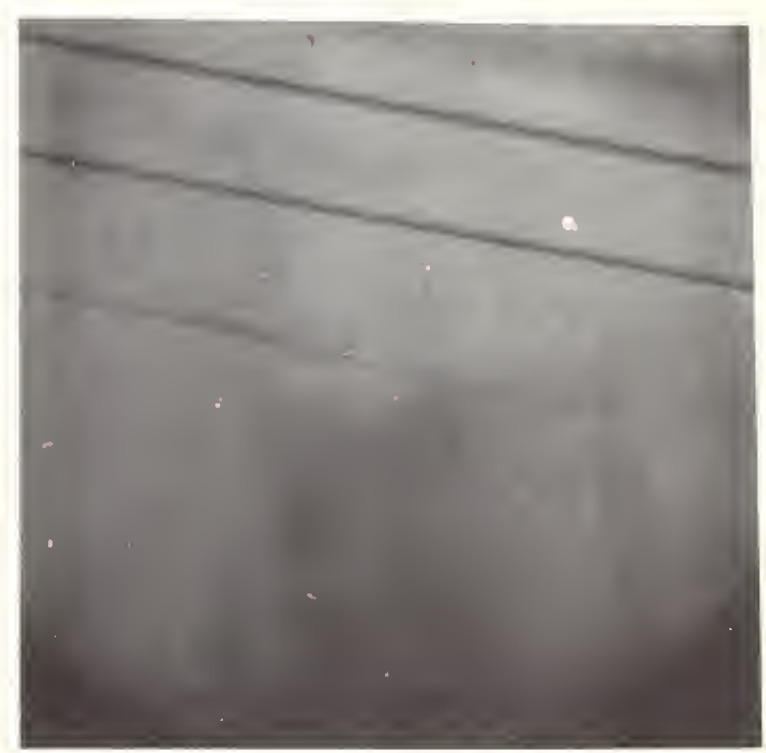

C-2 VERTICAL FIN PENETRAMETER FACING SOURCE

(D) 
Fig. 8: Continued

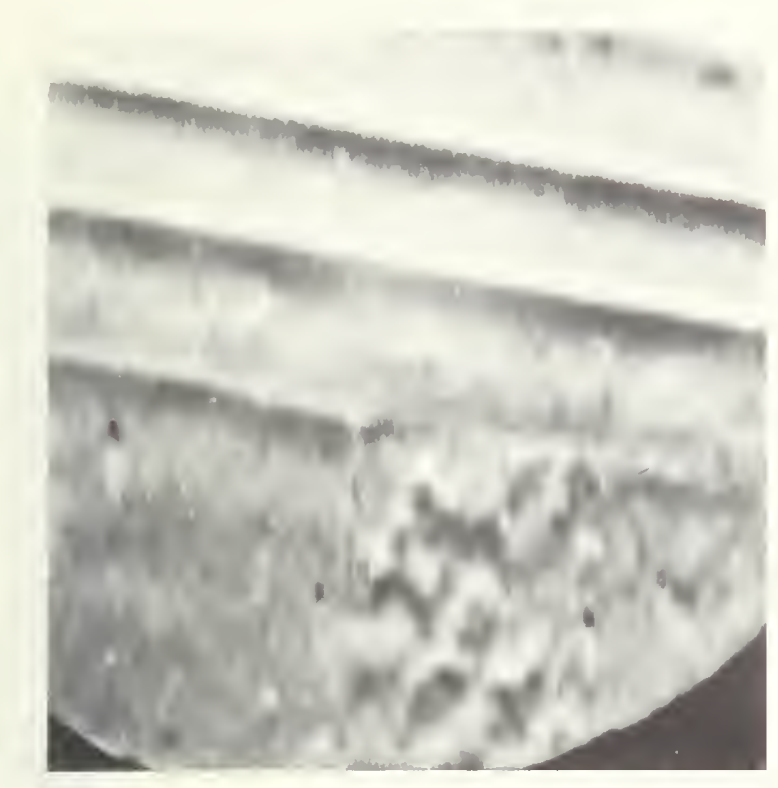

ANALOG EDGE ENHANCEMENT PENETRAMETER FACING CASSETTE

(E)

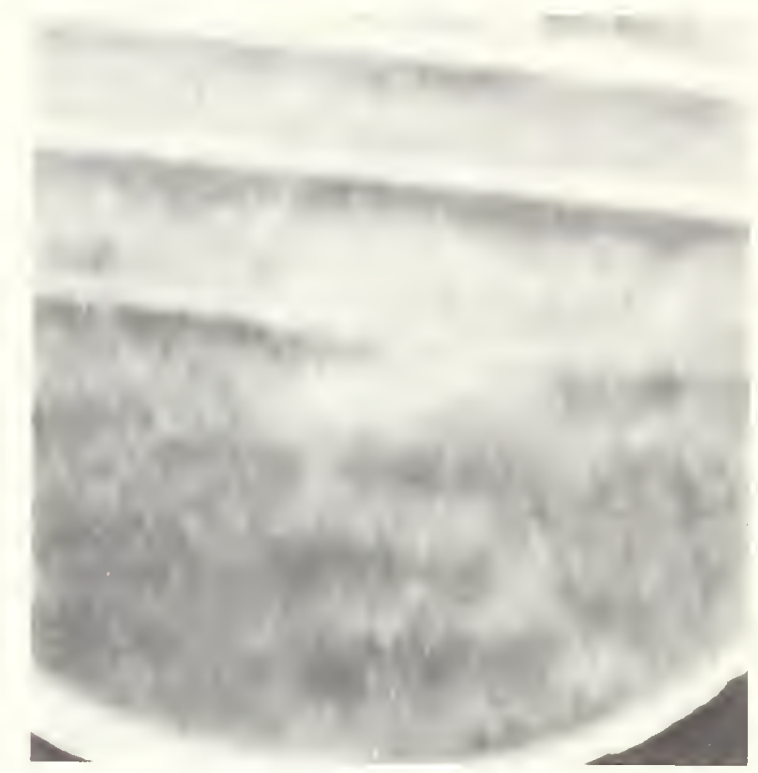

ANALOG EDGE ENHANCEMENT PENETRAMETER FACING SOURCE

(F) 

6. 2-C Exposure Series 2: Results and Conclusions

(a) Corrosion signatures can be visualized using $\mathrm{Gd}_{2} \mathrm{O}_{2} \mathrm{~S}$ converters with the penetrameter placed on either side of the 7 in.-thick fin, using an L/D ratio of 200:1. The apparent contrast was not as high as that obtained with Gd foil, as illustrated in Figures $7 \mathrm{C}$ and $7 \mathrm{D}$.

(b) The exposure time required using a $\mathrm{Gd}_{2} \mathrm{O}_{2} \mathrm{~S}$ converter was 15 min. for a L/D ratio of 200:1.

(c) Image edge enhancement aided in identifying the corrosion signature on either side of the fin with a L/D ratio of 200:1.

(d) When the $L / D$ ratio was reduced to $43: 1$ using a $\mathrm{Gd}_{2} \mathrm{O}_{2} S$ converter, the corrosion signature could only be visualized with the penetrameter placed between the cassette and the fin as illustrated in Figure $8 C$. All image detail was eliminated due to geometrical unsharpness when the corrosion penetrameter was placed on the source side of the fin as shown in Figure 80 .

(e) The exposure required $45 \mathrm{sec}$. to complete.

(f) Edge enhancement did aid in the visualization of the penetrameter when it was placed between the fin and cassette, however, played little role in the detection of the corrosion signature when the penetrameter was placed on the source side of the cassette.

\section{3-A Exposure Series 3A}

The principal objectives of this exposure series was to determine the effect on penetrameter $\mathrm{P}-1$ image quality when the $\mathrm{Gd}_{2} \mathrm{O}_{2} \mathrm{~S}$ converter 
and Kodak Type $M$ film were replaced by a ${ }^{6}$ LiF/Zns converter and lightsensitive Kodak Type Blue Brand film. The radiographic parameters of interest in this series of exposures is given in Table $3 \mathrm{~A}$ below.

Table 3A: Exposure Series 3A: Radiographic Parameters

Converter

Film Type

L/D Ratio

Exposure Time/Fluence

Neutron Beam Cd Ratio

Penetrameter

object
${ }^{6}$ LiF/Zns

Kodak Blue Brand

200:1

$5 \mathrm{sec} . / 1 \times 10^{6} \mathrm{n}-\mathrm{cm}^{-2}$

500:1

$p-1$

C-2 Vertical Fin Section

Radiographic data from Exposure $3 A$ are illustrated in Figure $9 A$ through $9 \mathrm{~F}$.

(4) Significant Parameter Change

\section{3-B Exposure Series 3B}

This series of exposure was made to observe the effect of reducing the system L/D ratio from $200: 1$ to $43: 1$ on the image quality of the $P-1$ penetrameter. The ${ }^{6}$ LiF/Zns in combination with Kodak Blue Brand film imaging method remained the same as in Series $3 A$. The radiographic parameters employed in these series are presented in Table $3 B$ below. 
Fia. 9: Exposure Series 3A: Radiographic Data

PENETRAMETEP

(A)

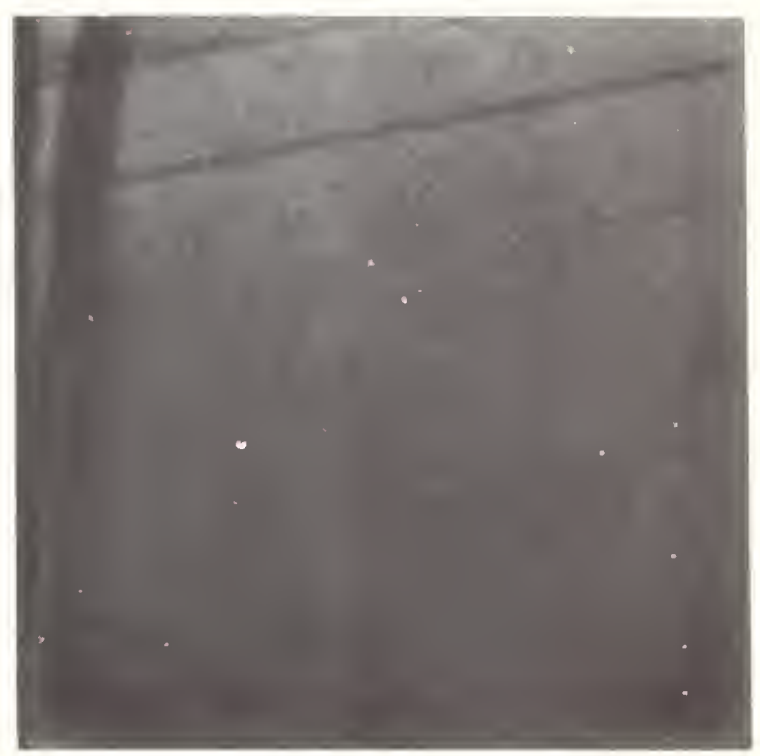

C-2 VERTICAL. FIN

(B)

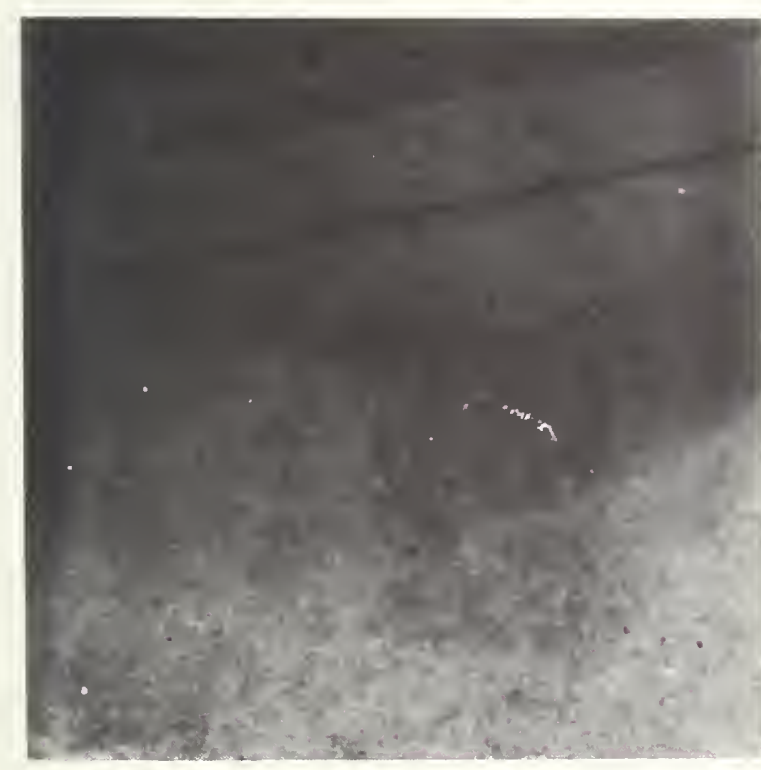

C-2 VERTICAL FIN PENETRAMETER FACING CASSETTE
(C)

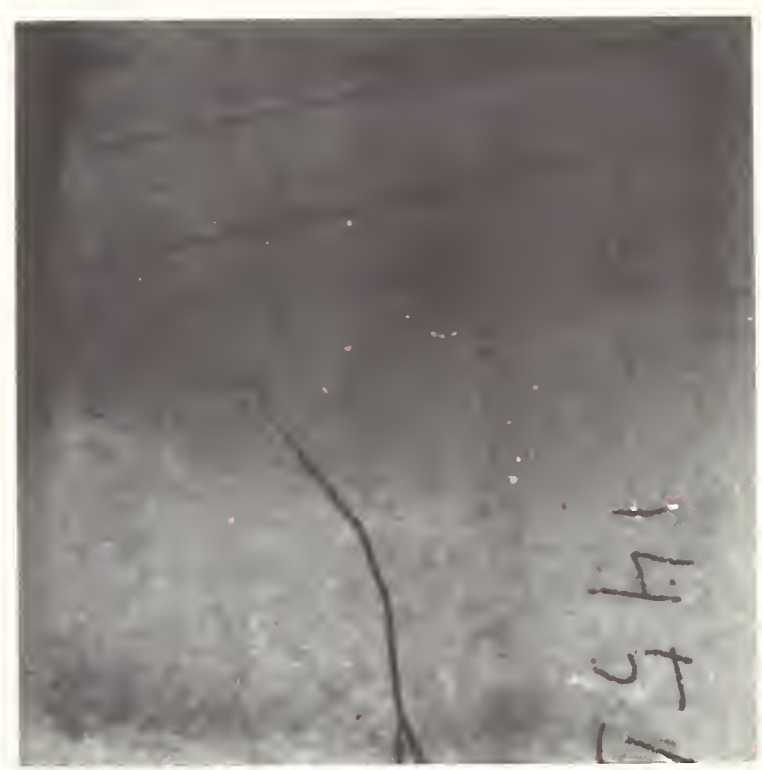

C-2 VERTICAL FIN PENETRAMETER FACING SOURCE

(D) 

Fig. 9: Continued

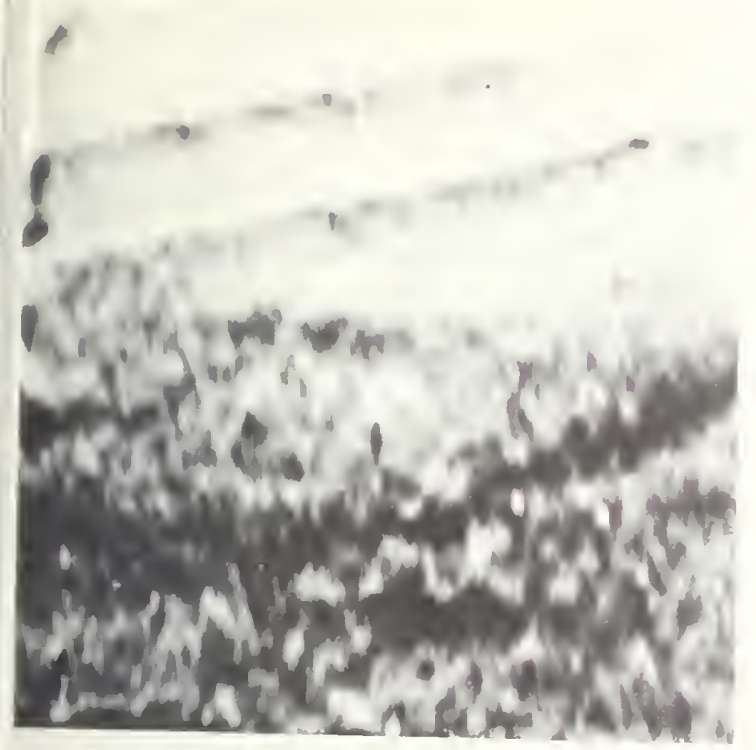

NALOG EDGE ENHANCEMENT PENETRAMETER FACING CASSETTE.

(E)

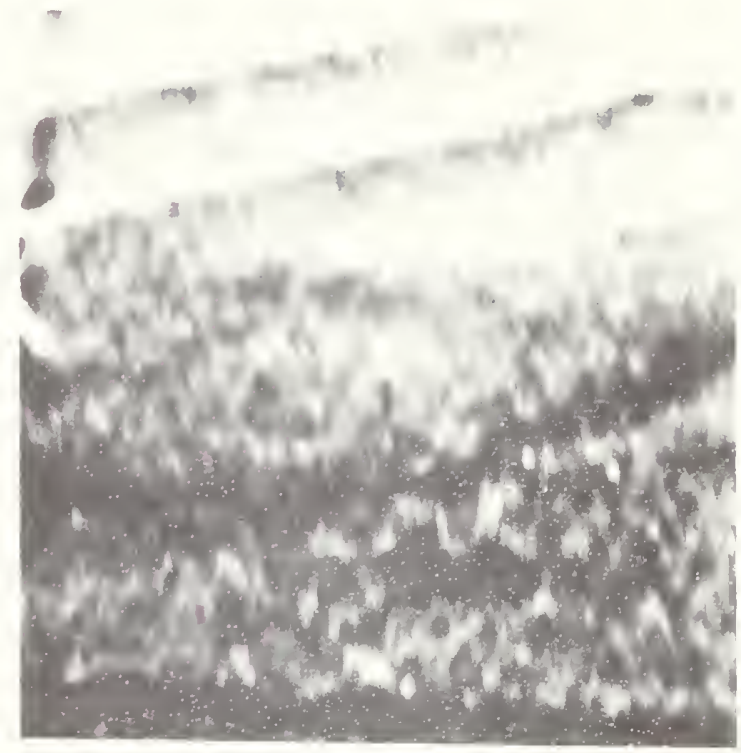

ANALOG EDGE ENHANCEMENT PENETRAMETER FACING SOURCE

(F) 


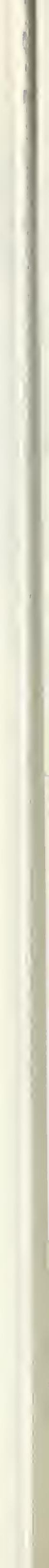


Table 3B: Exposure Series 3B: Radiographic Parameters

Converter

Film Type

L/D Ratio

Exposure Time/Fluence

Neutron Beam Cd Ratio

Penetrameter

Object
${ }^{6}$ LiF/Zns

Kodak Blue Brand

43:1

$0.2 \mathrm{sec} . / 1 \times 10^{6} \mathrm{n}-\mathrm{cm}^{-2}$

500: 1

$p-1$

C-2 Vertical Fin Section

The radiographic data derived from these exposures is illustrated in Figures $10 \mathrm{~A}$ through $10 \mathrm{~F}$.

(5) Significant Parameter Change

6. 3-C Exposure Series 3: Results and Conclusions

(a) Using a Nuclear Enterprise NE $421^{6}$ LiF/Zns light-emitting converter in conjunction with Kodak Blue Brand film and a $L / D$ ratio of $200: 1$, it was possible to visualize the corrosion signature when the penetrameter was placed between the vertical fin and cassette. The image quality was so poor however, that it could easily be confused with the scintillator mottling as illustrated in Figure $9 \mathrm{C}$.

(b) The exposure time required was $5 \mathrm{sec}$.

(c) When the corrosion penetrameter was placed on the source side of the fin section, it was impossible to differentiate accurately between the corrosion signature and the background mottiing.

(d) Edge image enhancement provided no useful purpose in the visualization of the corrosion signature with the penetrameter on either side of the film. 
Fig. 10: Exposure Series 3B: Radiographic Data

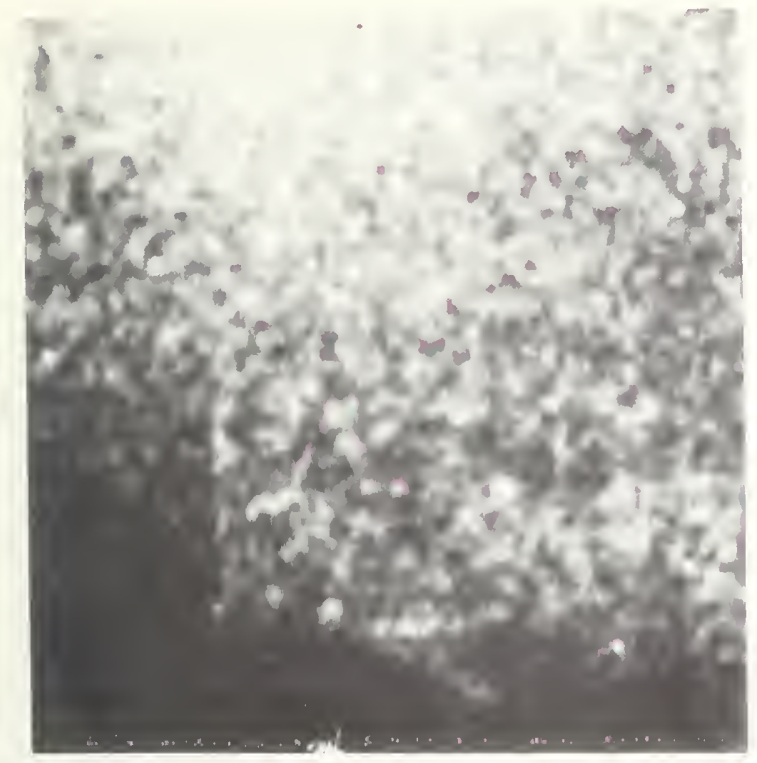

PENETRAMETER

(A)

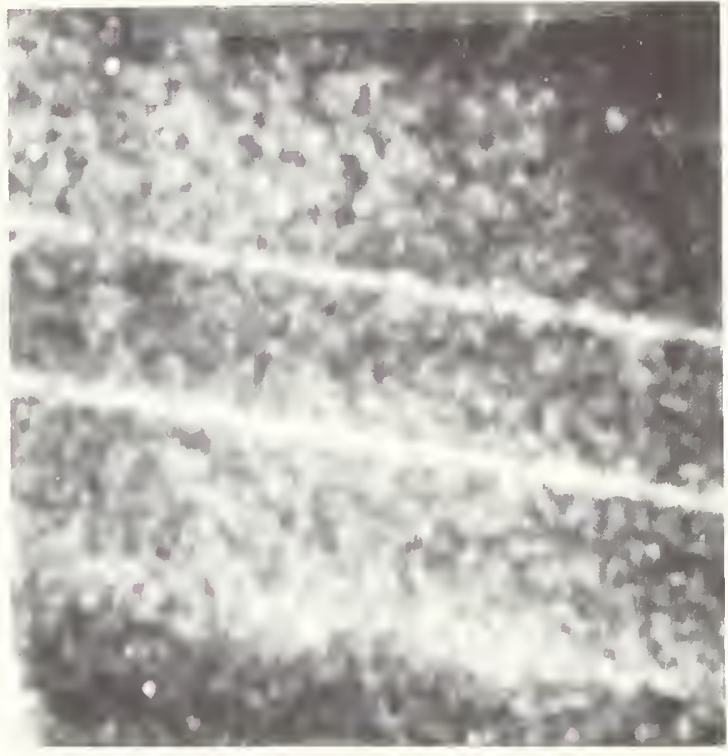

C-2 VERTICAL FIN

(B)

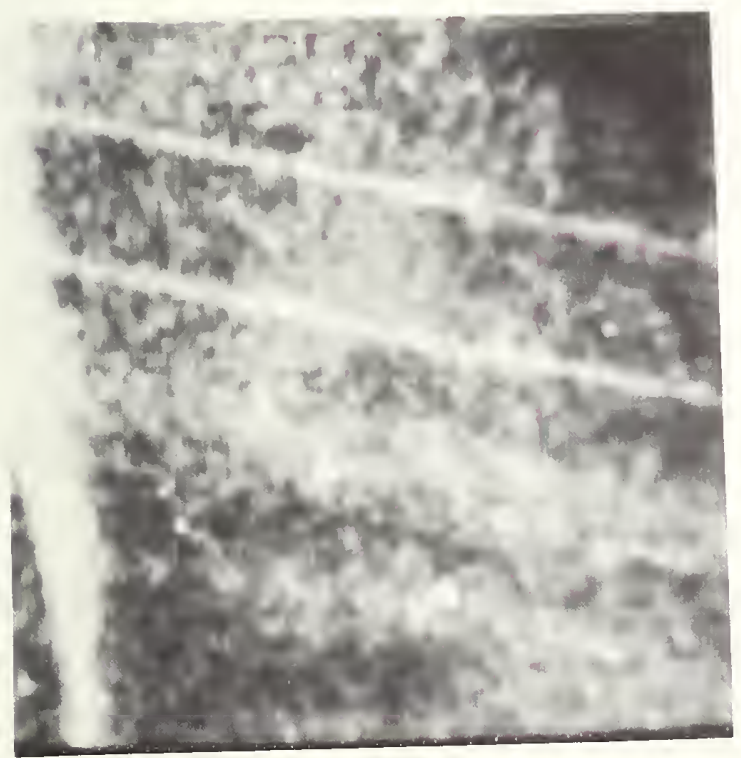

C-2 VERTICAL FIN PENETRAMETER FACING CASSETTE

(C) $-26-$

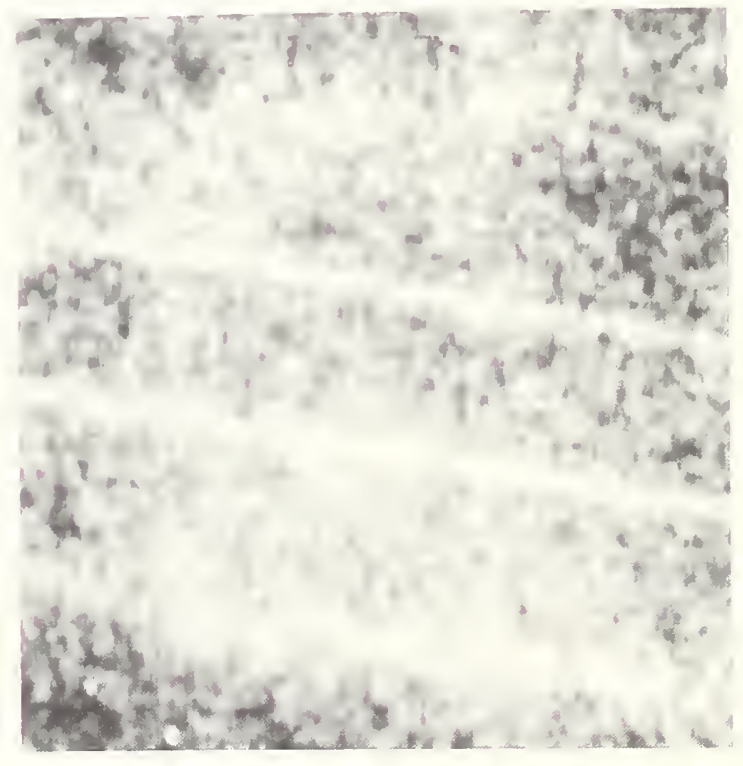

C-2 VERTICAL FIN PENETRAMETER FACING SOURCE

(D) 

Fia. 10: Continued

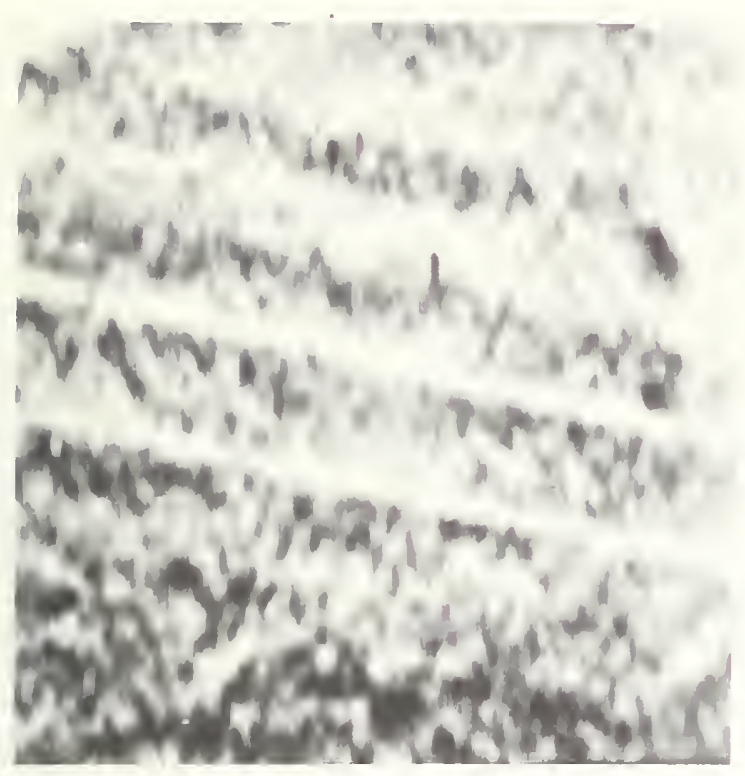

ANALOC EDGE ENHANCEMENT PENETRAMETER FACING CASSETTE

(E)

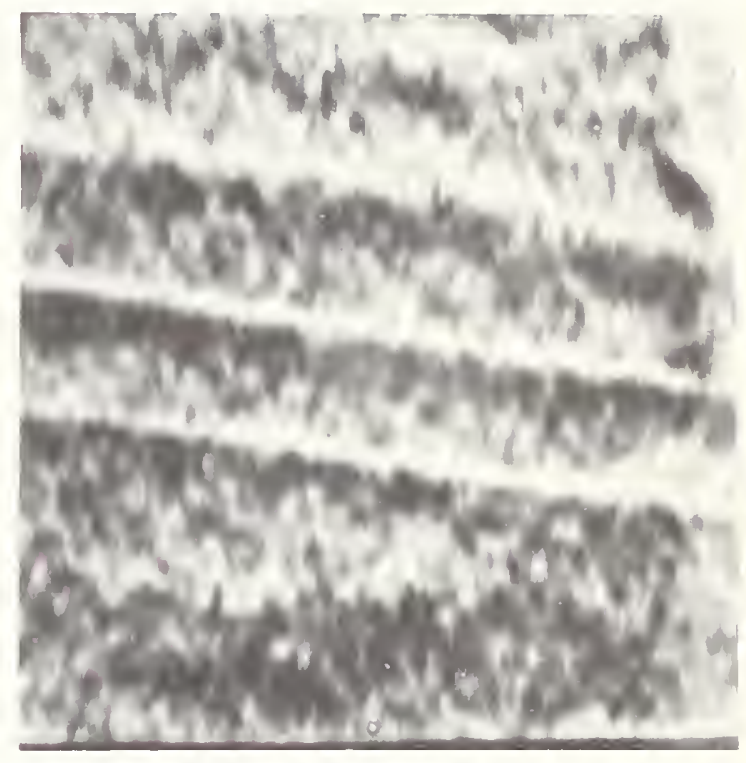

ANALOG EDGE ENHANCEMENT PENETRANETER FACING SOURCE

(F) 
(e) When the $L / D$ ratio was reduced to $43: 1$, it was impossible to accurately distinguish between the corrosion signature and the background mottling with the penetrameter on either side of the vertical fin.

(f) The exposure time required for this radiograph was approximately $0.2 \mathrm{sec}$.

\section{4-A Exposure Series 4: General}

These investigations were conducted in an attempt to define the lower limit of corrosion detectability in aircraft-grade aluminum utilizing reactor-based neutron radiographic procedures. A set of four calibrated corrosion penetrameters $\mathrm{P}-2$ were fabricated from 0.062 in.-thick aluminum plates which had been subjected to a salt water spray/ $/ \mathrm{SO}_{2}$ gas environment for $0,4,8$ and 15 days. These penetrameters are illustrated in Figure 4. Thermal neutron radiographs were made of the seven inch thick $\mathrm{C}-2$ vertical fin with calibrated penetrameters placed on the cassette side of the C-2 vertical fin.

The radiographic parameters employed for this set of exposures are given in Table 4 below.

Table 4: Exposure Series 4: Radiographic Parameters

Converter

Film Type

L/D Ratio

Exposure Time/Fluence

Neutron Beam Cd Ratio

object

Penetrameters

The penetrameter calibrations are outlined in Table 5 below.
0.0005 in.-Thick Vapor Deposited Gd Kodak Type $M$ $100: 1$

$30 \mathrm{~min} . / 18 \times 10^{8} \mathrm{n}-\mathrm{cm}^{-2}$

500:1

C-2 Vertical Fin

P-2-1 through P-2-4 
Table 5: Penetrameter Calibration

Penetrameter Number

$\begin{array}{lr}P-2-1 & 0 \\ P-2-2 & 4 \\ P-2-3 & 8 \\ P-2-4 & 15\end{array}$
15
Exposure Period to Salt Water Spray $/ \mathrm{SO}_{2}$ Gas Environment (Days) 4 8

The radiographic data illustrated in Figures $11 \mathrm{~A}, 11 \mathrm{C}, 11 \mathrm{E}$ and $11 \mathrm{G}$ are video reproductions of penetrameters subjected to the corrosive environment for periods of $0,4,8$ and 15 days respectively. The data illustrated in Figures 11B, 110, I1E and $11 \mathrm{G}$ illustrate the edge enhanced reproductions respectively of these radiographs. It should be noted that the artifacts which appear as white dots in the neutron radiographic images were the result of dirt or other foreign neutron absorbing matter on the inside of the airfoil and were not images of the corrosion penetrameter.

6.4-B Exposure Series 4: Results and Conclusions

(a) Thermal neutron radiographs of the four calibrated corrosion

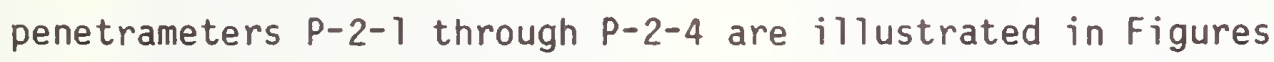
I1A, I1B, I1C and 110. These penetrameters were corroded with a salt water spray/ $\mathrm{SO}_{2}$ gas mixture for periods of $0,4,8$ and 15 days respectively.

(b) In the corrosion radiographs illustrated in figures $11 \mathrm{~A}$ and $11 \mathrm{C}$, the corrosion cannot be distinguished from the background noise as shown in the edge enhanced illustrations in 
Fig. 11: Exposure Series: Radiographic Data

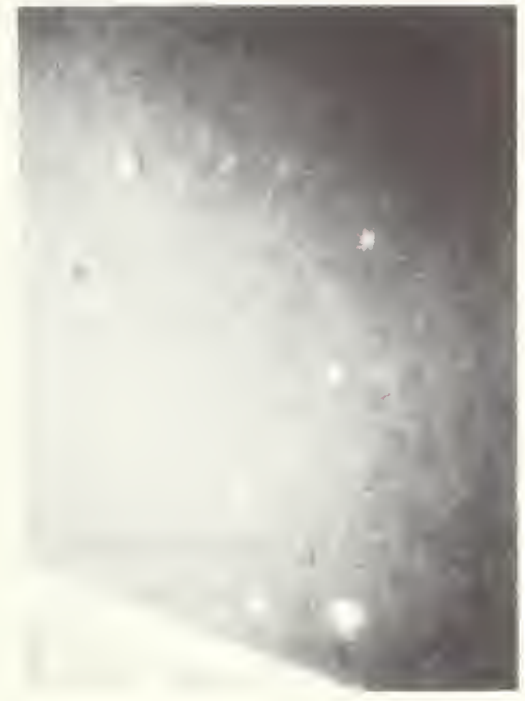

(A)

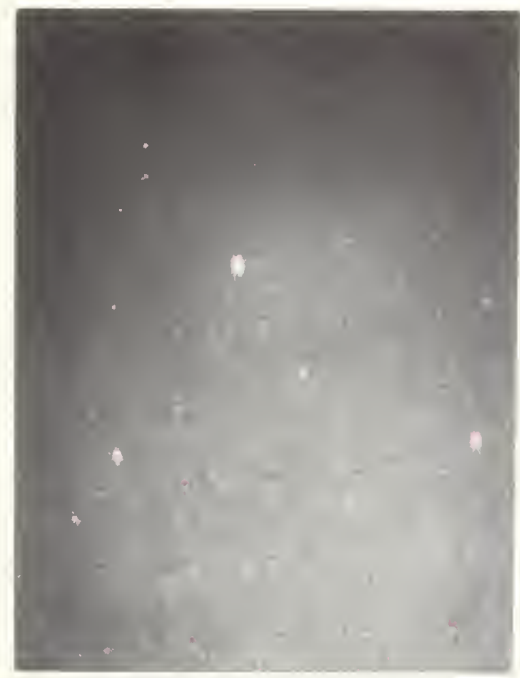

(C)

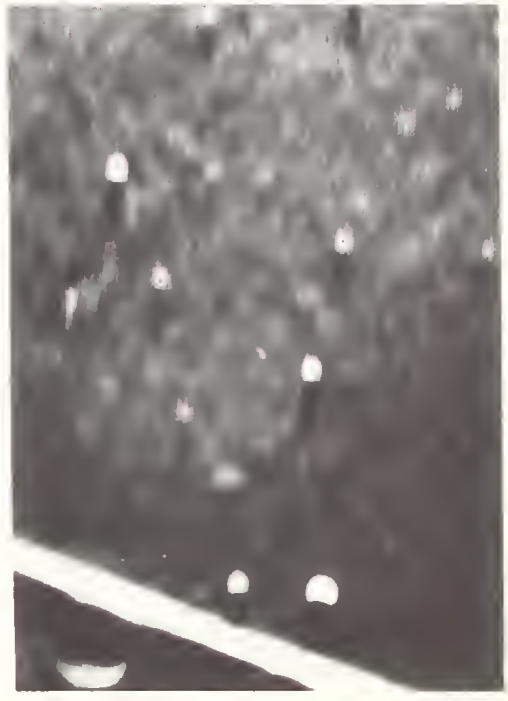

(B)

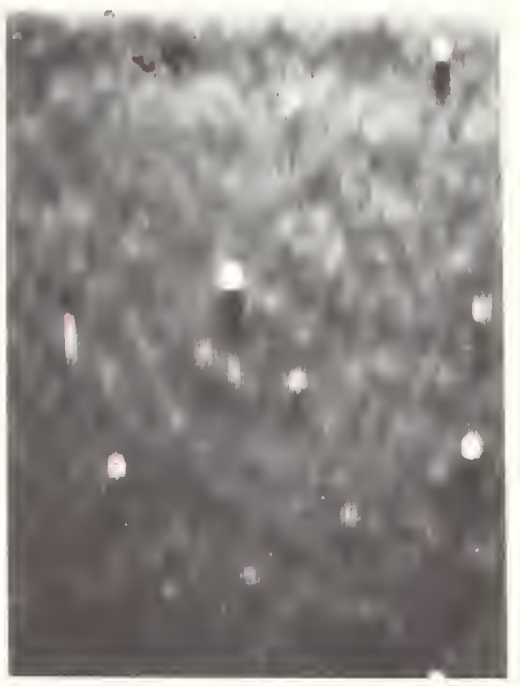

(D) 


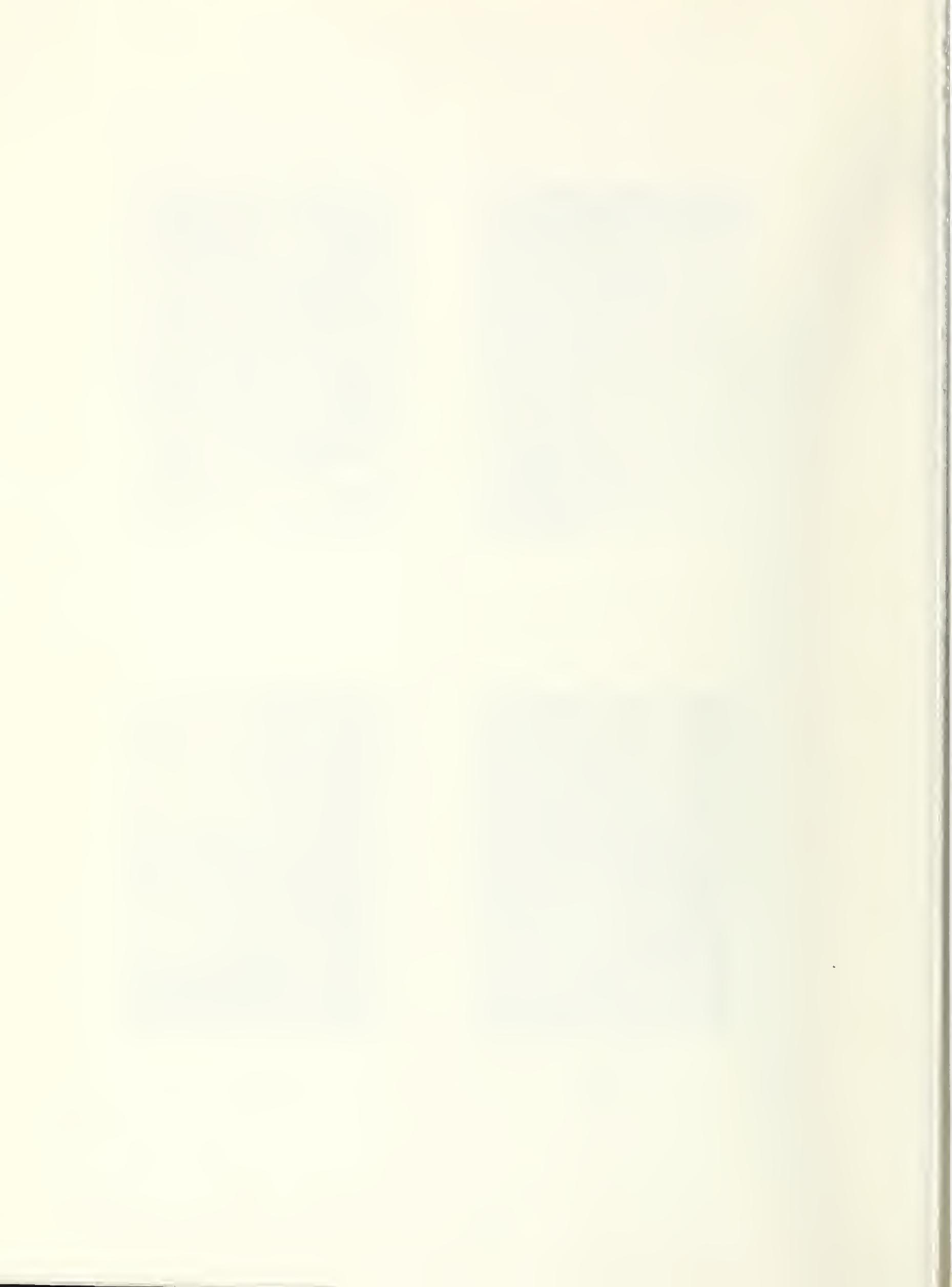


Fig. 11: Continued

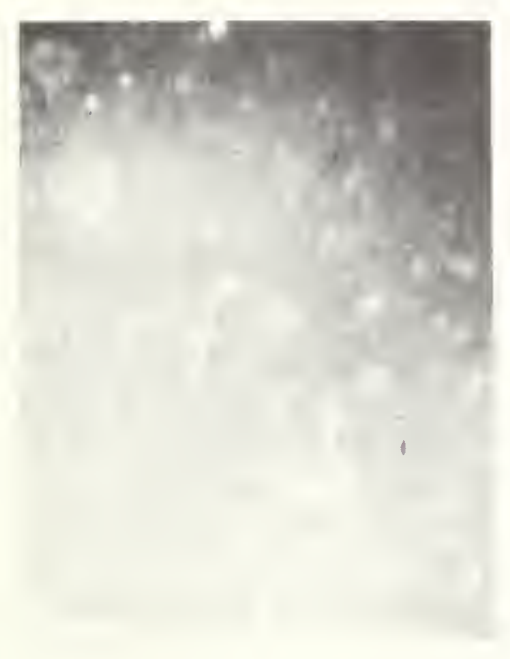

(E)

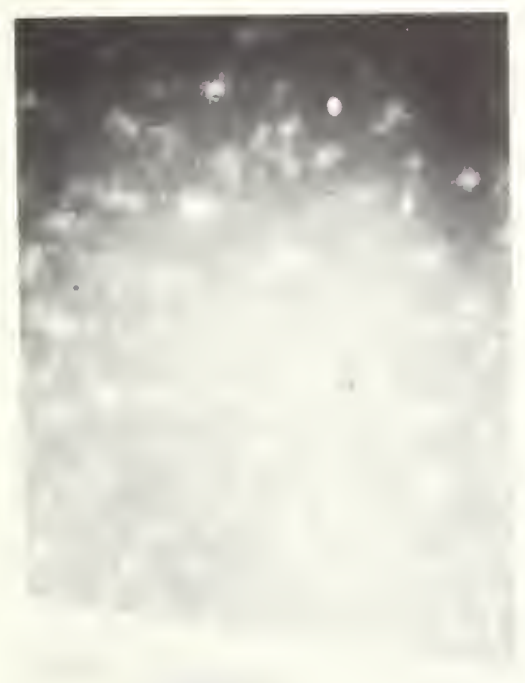

(G)

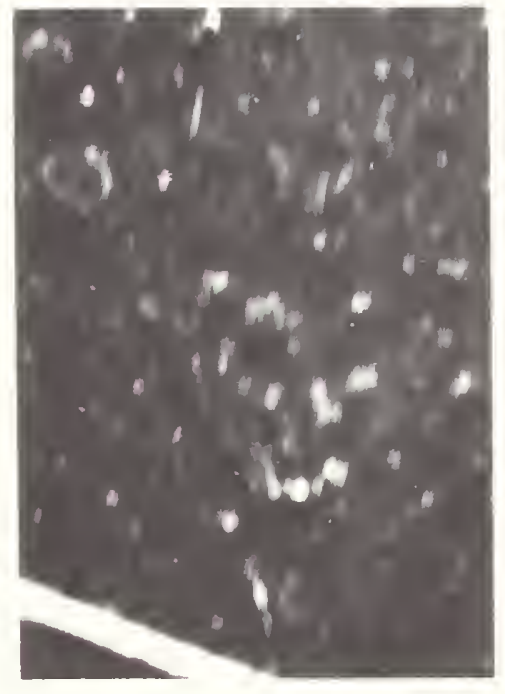

(F)

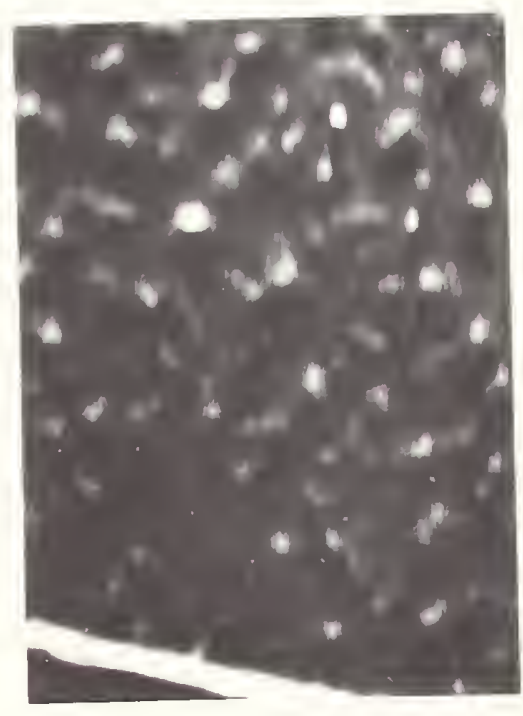

(H) 
Figures $11 E$ and $I I F$. It is likely that the mottled background noise is due to the neutron response to the fin paint.

(c) Environment induced corrosion can be observed without image enhancement in the 8 and 15 day samples illustrated in Figures $11 \mathrm{C}$ and 110 respectively. Image enhancement serves to render the corrosion images more observable as illustrated in Figures $11 G$ and $11 \mathrm{H}$.

7.0 Quantification of Corrosion

Based on the experience gained in these preliminary investigations, empirical quantification of corrosion appears to be a possibility, either by isodensity scanning of neutron radiographs and comparison of scans of the corrosion areas with sound aluminum, or by digital image enhancement techniques. This conclusion is based on the fact that differences in corrosion density in the $P-1$ penetrameter could be visualized and that a minimum level of detectability could be established with the plaque penetrameters $\mathrm{P}-2-1$ through $\mathrm{P}-2-4$. Penetrameter $\mathrm{P}-1$ was more easily seen then the $P-2$ series because of the greater degree of induced corrosion.

\subsection{Remarks and Qualifications}

It should be noted that the approach taken in these investigations was a very practical one in that the radiographic data obtained using ideal laboratory conditions was taken as a base, e.g., relatively high resolution imaging methods were employed. Comparative radiographic data were then obtained by varying the radiographic parameters to simulate a low-resolution system as might be the case in a transportable field unit neutron radiography system. 
In the preparation of this report the conclusions reached were derived from actual radiographic data and not from photographic reproductions.

Photographic reproduction of high density radiographs was very difficult to accomplish for this report, e.g., the overexposure of Figure 5 compared to Figure 6 is not real, but is due to the photographic reproduction.

The data obtained in this work was limited to the use of filmconverter imaging systems. No attempt was made to evaluate scintillatorcoupled real time imaging systems.

\subsection{Summary}

The significant results obtained from these investigations at the National Bureau of Standards may be summarized conclusively in the following statements.

(1) Environment-induced corrosion in aircraft-grade aluminum can be detected with a high degree of sensitivity with thermal neutron radiographic interrogation.

(2) The fluence (integrated neutron flux) at the image plane required to visualize corrosion with conventional imaging methods e.g., gadolinium converter in conjunction with a medium contrast industrial x-ray film at density of 2.5 , is approximately $4 \times 10^{8} \mathrm{n}-\mathrm{cm}^{-2}$. Assuming that a transportable neutron radiography system were capable of producing $1.5 \times 10^{4}$ $\mathrm{n}-\mathrm{cm}^{-2}-\mathrm{sec}^{-1}$ at a L/D ratio of $40: 1$, an exposure of $7.2 \mathrm{hrs}$ would be required.

(3) At a $L / D$ ratio of $40: 1$, the corrosion signature of both surfaces of a thick object, e.g., a wing or airfoil, must be 
interrogated individually. This is due to the fact that geometrical unsharpness obliterates signature detail on the surface opposite the cassette.

(4) The possibility of corrosion quantification does exist, based on investigation with standard corrosion plaque penetrameters.

(5) Although the use of ${ }^{6} \mathrm{LiF} / \mathrm{ZnS}$ light emitting converters is the most efficient method by which thermal neutron beams can be imaged, the results are inadequate for unambiguous corrosion signature analysis using presently available converters. The reasons for this are described below.

10.0 Recommendations for Future Work at NBS

10.1 Converter Development

The most efficient light-emitting neutron imaging system in so far as speed is concerned consists of a physical mixture of ${ }^{6}$ LiF and $\mathrm{ZnS}$ powders. The components are held in suspension with a binder and settled on a thin aluminum substrate. The nuclear reaction which takes place is ${ }^{6} \operatorname{Li}(n, T) \alpha$, the tritons and alpha particles producing light in the ZnS scintillator.

The neutron radiographic images produced when this type of imaging screen is placed in intimate contact with light-sensitive film is quite grainy, exhibiting poor resolution. This is due, in fact, to several factors which include:

(a) The fact that the matrix is composed of powders having a finite grain size. If this grain is too coarse, a granular image will result. 
(b) The ${ }^{6}$ LiF/ZnS is partially transparent to light generated within the matrix, making it possible for light generated at one point to be scattered and emitted at a neighboring site.

(c) Light sensitive films generally tend to exhibit greater grain than industrial $x$-ray films.

We propose that a funded $R$ \& D program be initiated at NBS to develop a neutron-sensitive scintillating converter which will overcome the aforementioned problems of the presently available continuous ${ }^{6}$ Lif/ZnS thermal neutron imaging screens. Specifically, (1) we propose to size the ${ }^{6}$ LiF/ZnS components so that only the finest grains available are employed to mix the final matrix using a fluorocarbon binder and (2) to break the initial continuous screen into a myriad of discrete information centers, or cells in order to eliminate the cross-talk generated as a result of the light transmission within the scintillator screen matrix. We have in mind to deposit the converter matrix in individual cells using chemically milled meshes having cells of approximately 0.001 in. on a side separated by 0.005 in. walls to minimize cross-talk.

\subsection{Real-Time Imaging Methods for Corrosion Detection}

Pending the outcome of the screen-development work, we propose that an evaluation of state-of-the-art real-time imaging systems be conducted for corrosion detection under field conditions. It would be most cost effective to evaluate the available real-time imaging systems on a lease basis.

This method has the advantage of speed based on the assumption that a suitable fast imaging screen can be developed which would provide the required resolution. 


\subsection{Corrosion Quantification Standard Penetrameter Development}

The quantification of detectable corrosion could produce an economic impact on military aircraft maintenance costs based on the assumption that short exposure times can be achieved. By being able to quantify the corrosion, it should be possible to predict the time at which a defective area of skin or component should be replaced, rather than replacement on a preventative maintenance basis. This is contingent on the fact that a fast, high resolution imaging screen can be developed which would result in reasonable exposure times.

We propose that several avenues of investigations towards this end be pursued, e.g.

(1) Automated radiographic image analysis based on the isodensity pattern comparison with standard corrosion penetrameters or edge enhanced shadow analysis.

(2) Microchemistry of actual aircraft corrosion samples to aid in the fabrication of standard corrosion penetrameters for use as Standard Reference Materials.

(3) Subtraction of $x$-ray data from neutron data to eliminate the radiographic interferences caused by structural airframe thickness variation. 
U.S. DEPT. OF COMM.

BIBLIOGRAPHIC DATA SHEET

TITI.F AND SUIBTITI.I:

3. Recipient's Accession No.

THE MACROSCOPIC DETECTION OF CORROSION IN ALUMINUM AIRCRAFT STRUCTURES WITH THERMAL NEUTRON BEAMS AND FILM IMAGE METHODS

5. Publication Date

6. Performing Organization Codc

AUTIIOR(S)

Donald A. Garrett

PERFORMING ORGANIZATION NAME AND ADDRESS

NATIONAL BUREAU OF STANDARDS

DEPARTMENT OF COMMERCE

WASHINGTON, D.C. 20234

.. Sponsoring Organization Name and Complete Address (Street, Cily, State, ZIP)

13. Type of Report \& Period Covered

14. Sponsoring Agency Code

5. SUPPLI:MENTARY NOTIS

6. ABSTRAC:T (A 200-word or less factual summary of most significant information. If document includes a significant bibliography or literature survey, mention it here.)

The primary objective of this investigation was to determine the feasibility of etecting corrosion in aluminum Naval aircraft components with neutron radiographic nterrogation and the use of standard corrosion penetrameters. Secondary objectives in:luded the determination of the effect of object thickness on image quality, the defining if minimum levels a dectability and a preliminary investigation of means whereby the deiree of corrosion could be quantified with neutron radiographic data.

All objectives were met and may be summarized as follows: (1) Environment-induced : orrosion can be detected with high sensitivity by thermal neutron radiographic interrojation, (2) the fluence at the image plane required to visualize corrosion with conventional imaging methods e.g., a gadolinium converter in conjunction with a medium contras: industrial $x$-ray film at density of 2.5 , is approximately $4 \times 10^{8} \mathrm{n}-\mathrm{cm}^{-2}$. Assuming that a transportab] e neutron radiography system were capable of producing a flux of $1.5 \times 10^{4}$ $n-\mathrm{Cm}^{-2}-\mathrm{sec}^{-1}$ at an $\mathrm{L} / \mathrm{D}$ ratio of $40: 1$, an exposure of 7.2 hours would be required, (3) at an $L / D$ ratio of $40: 1$, the corrosion signatures of both surfaces of a thick object, e.g., a wing or airfoil, must be interrogated individually. This is due to the fact that geometrical unsharpness obliterates signature detail on the surface opposite the cassette. (4) The possibility of corrosion quantification does exist. This conclusion is based on an investigation with standard corrosion plaque penetrameters, and (5) although the use

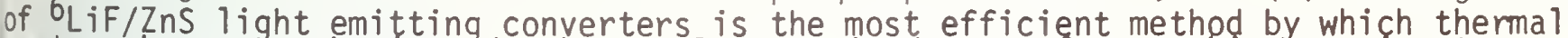
neutron beams can be imaged, the results are inadeauate for unambiguous signature analys s with presently available converters.

17. KEY WORIS (six to twelve entries; alphabetical order; capitalize only the first letter of the first key word unless a proper name; separaled by semicolons)

Aircraft corrosion; corrosion; corrosion characterization; corrosion detection; corrosion quantification; hidden corrosion detection with neutron beams; neutron radiography

18. AVAILABILITY

$$
\text { X Unlimited }
$$

For Official Distribution. Do Not Release to NTIS

[? Order From Sup. of Doc., U.S. Government Printing Office Washington, D.C. 20402, SD Cat. No. C13

X Order IFrom National Technical Information Service (NTIS) Springficld, Virginia 22151

\begin{tabular}{|l|l|}
\hline $\begin{array}{l}\text { 19. SECURITY CLASS } \\
\text { (THIS REPORT) }\end{array}$ & 21. NO. OF PAGES \\
UNCLASSIFIED & \\
\hline $\begin{array}{l}\text { 20. SECURITY CLASS } \\
\text { (THIS PAGE) } \\
\text { UNCLASSIFIED }\end{array}$ & 22. Price \\
\hline
\end{tabular}


